\title{
Formulation and characterization of pulmonary drug delivery systems
}

\author{
SABRINA MAGRAMANE, ZSÓFIA PÁPAY, BÉLA TURBUCZ, ISTVÁN ANTAL* \\ Department of Pharmaceutics, Semmelweis University, Hőgyes Str. 7., Budapest, H-1092 \\ *Corresponding author: István Antal \\ E-mail: antal.istvan@pharma.semmelweis-univ.hu
}

Received: 5 July 2019 / Accepted: 5 July 2019 / Published online: 24 July 2019

\begin{abstract}
The inhalation therapy is one of the oldest drug delivery methods known. The significance of inhalation can be understood notably through its remarkable history. The goals of this review are to explore the pulmonary drug delivery, its significant relevance and various advantageous properties, particularly due to the physiology of the lungs. The drug delivery into the lungs can be provided by several inhalation instruments presently accessible on the market such as nebulizers, MDIs, and DPIs. Supplementary devices suchlike spacers for instance are also available in order to optimize the therapy results. The efficiency of these devices depends on several parameters of the formulation used, as well as its deposition in the lungs. Therefore, this review focuses on the meticulous testing performed on both the formulation and the device carrying it in the interest of insuring safety, quality, and efficacy of the final product. Ultimate$l y$, the pulmonary drug delivery represents a substantially advantageous alternative route of administration to obtain a systemic effect as well. This review aims to the better understanding of the development of pulmonary dosage forms and its complex process which requires extensive considerations and thorough optimization.
\end{abstract}

Keywords: pulmonary drug delivery, inhalation, lung deposition, particle size, inhaled formulations.

\section{Introduction - Historical review of inhalation for drug delivery}

The substantial progression witnessed in the development of inhalation devices may indicate that pulmonary drug delivery is a novel route of administration. However, the use of treatments through inhalation for therapeutic intents has existed for thousands of years and has been practised in numerous civilizations (Figure 1). Four thousand years ago, in India, pulverized jimsonweed (Datura stramonium) and angel's trumpet ( $D a-$ tura ferox) were mixed with natural ingredients such as pepper or ginger and smoked for their bronchodilating therapeutic properties, due to their alkaloids content [1, 2]. Apart from that, the oldest known mention of the use of inhalation for therapeutic purposes dated back to $1554 \mathrm{BC}$ and was found in the Ebers papyrus. In this Egyptian papyrus scroll, a depiction of patients who seem to have trouble breathing can be found. Black henbane (Hyoscyamus niger) is put on hot bricks, and the vapour generated is respired by the patients through a stem of reed attached to a pot placed

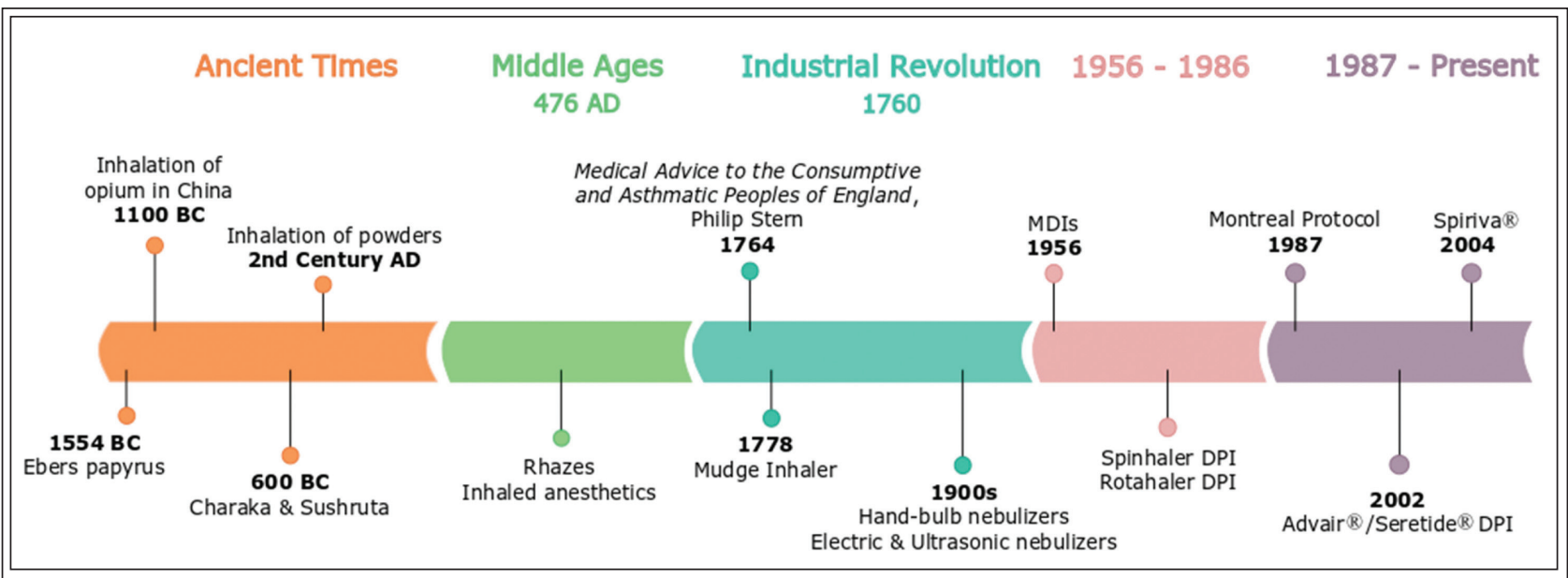

Figure 1 Timeline of the History of inhalation therapy 
over the burning plant. Hyoscyamus niger's remedial properties come from its tropane alkaloids contents, particularly atropine and its anticholinergic properties [3].

In $1100 \mathrm{BC}$, opium was smoked using pipes and incense burners for both therapeutic and recreational purposes in China. This marks one of the most notable uses of the pulmonary route of administration, although Avicenna thoroughly detailed opioids' toxicity and dissuaded their usage [3].

In $600 \mathrm{BC}$, a description of the treatment of asthma by therapeutic inhalation was detailed in the scriptures of Charaka and Sushruta (notorious Indian physicians). Datura stramonium (which contains atropine) was used against asthma symptoms, in the form of a cigarette or a pipe. In his writings, Charaka also describes steam inhalation and cigars (made of several natural ingredients such as the paste of turmeric) as asthma therapies [3].

In the second century AD, Galen suggested the use of powders of myrrh and nutgall through inhalation to reduce nasal and chest symptoms [3].

From the Middle Ages most therapies were based on the methods developed during the Ancient Times such as the smoking of opium or $D a-$ tura stramonium. One of the most groundbreaking approaches of the Middle Ages was made by the Arab physician Rhazes. He developed a liquid mixture of narcotic plants: opium, mandrake, and henbane. A sponge was then soaked in the solution and left to dry. Before surgery, the sponge was humidified and placed on the patient's mouth and nose. The patient would then inhale the fumes generated by the sponge. These vapours produce an anaesthetic effect [3].

With the start of the Industrial Revolution (1760-) came significant innovations, notably in manufacturing procedures. The respiratory drug delivery acquired a particular attention when the English physician Philip Stern declared that "the only possible way of applying medicines directly to the lung is through the windpipe". The inhalers created by Stern and English physician John Mudge amplified the popularity of the treatment of asthma through the inhalation of pharmaceutical drugs $[1,4,5]$. As a consequence, various ceramic inhalers were developed.

When it comes to drug inhalation, the therapeutic aerosol had to be prepared by either the physician or the patient himself. However, during the Industrial Revolution, the discoveries and advances made allowed for the aerosol to be made by a third party and even to be produced on a large scale. Furthermore, novel entities and techniques were designed, allowing for the active ingredient to be isolated, and its safety and potency to be improved. The Industrial Revolution era also marks the launch of nebulizers and early versions of dry powder inhalers (DPIs) [3].

The early 1900s were marked by the popularity of hand-bulb nebulizers delivering adrenaline chloride for its bronchodilating properties. In the $20^{\text {th }}$ century, new types of nebulizers were developed: the electric and the ultrasonic nebulizers [1].

The period between 1956 and 1986 brought the advances of pressurized metered-dose inhalers (MDIs) and later the dry powder inhalers which are still broadly used presently. The introduction of metered-dose inhalers (MDIs) started in 1956 $[1,2]$, among the first approved MDIs was the Medihaler-Ergotamine, a device delivering ergotamine tartrate for migraine therapy, which illustrates the early interest for the therapy of systemic conditions through the pulmonary route of administration [6]. Supplementary devices were also developed to ameliorate the efficacy of the inhalers and to facilitate patient coordination. Two DPIs, in particular, marked this period: the Spinhaler $^{\circledR}$ and the Rotahaler ${ }^{\circledR}$. The Spinhaler ${ }^{\circledR}$ delivered $20 \mathrm{mg}$ of sodium cromoglycate [1] from a gelatin capsule which is later on pierced by the device. The formulation aspects of this inhaler shaped the present formulation development of DPIs. The Rotahaler ${ }^{\circledR}$ delivered albuterol from a capsule which is later halved by the device [3].

The latest period since 1987 (marked by the signature of the Montreal Protocol eliminating CFC propellants) is characterized by a recordbreaking advancement in the pulmonary drug delivery with the rise of yearly sales from $\$ 7$ billion in 1987 to $\$ 36$ billion in 2014 [3]. In 2002, the introduction of Advair ${ }^{\circledR} /$ Seretide ${ }^{\circledR}$ delivering salmeterol xinafoate/ fluticasone propionate for the treatment of asthma resulted in the first multibillion- dollar DPI. Another example is the Spiriva ${ }^{\circledR}$ inhaler launched in 2004, delivering tiotropium. It was the first inhalation drug intended for the treatment of COPD (Chronic Obstructive Pulmonary Disease), which at the time was an inefficiently treated disease [6].

\section{Advantages of pulmonary drug delivery}

The pulmonary delivery is an interesting drug delivery route for locally acting treatments of lung diseases such as asthma. However, owing to the scientific development of pharmaceutical formula- 
tions and inhalation devices, pulmonary drug delivery plays an important role in delivering drugs systemically and treating systemic conditions such as diabetes, certain autoimmune diseases and some types of cancer [7]. Pulmonary delivery can be obtained via oral or nasal routes. However, higher drug deposition can be achieved with the former way. This can be attributed to the physiological structure of the human lungs. The respiratory tract has two distinct parts by function: the respiratory zone and the conducting airways [8]. According to Weibel's lung model - which is the simplest and widely used model - there are 23 socalled generations $(\mathrm{G})$ and the trachea $(\mathrm{G} 0)$ (Figure 2) [9]. The evolution starting from the trachea to the alveolar ducts can be described by decreased tube length and cross-sectional tube area, yet an increased number of tubes. In the lumen, the trachea has a width of approximately $2.5 \mathrm{~cm}$ while the alveolar ducts possess a diameter of only $0.2-0.5$ $\mathrm{mm}$. Thereby the airways have a surface area of about $2.5 \mathrm{~m}^{2}$, and that of the alveoli is about 100 $\mathrm{m}^{2}$. The mouth and nasal cavities, pharynx and larynx, also belong to the conducting zone and are responsible for carrying the gas to the site of the gas exchange, as well as filter, warm up and hu-

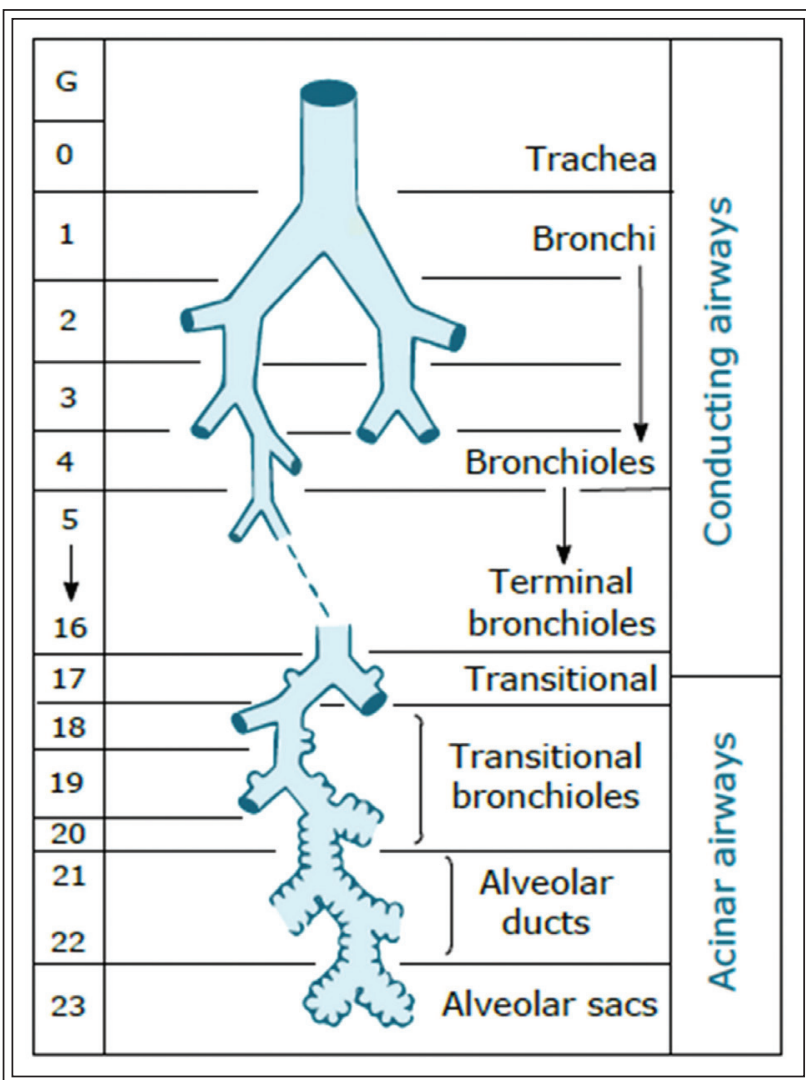

Figure 2 Weibel's lung model (based on [8]) midify the inspired air. The gas exchange occurs from the respiratory bronchioles (G17) to the alveolar sacs (G23) $[8,10]$.

Due to their physiological properties, namely a large surface area beneficial for absorption $\left(100 \mathrm{~m}^{2}\right)$, the lungs possess a unique platform for drug delivery, whether locally or systematically. This also allows a rapid onset of action of drugs. There are no food effect or $\mathrm{pH}$ problems, and the first-pass metabolism can be avoided. Consequently, a decreased effective dose can be used, and fewer side effects could occur.

\section{Inhalation devices}

The painless drug delivery - compared to injections - could increase the patient's compliance. However, it is necessary to inform them about the proper manipulation of the inhalation devices. Up to $50 \%$ of the patients misuse the inhalers due to the incoordination of the inhalation with the actuating element. Three main types of devices are available on the market: nebulizers, pressurized metered-dose inhalers (pMDIs) and dry powder inhalers (DPIs) (Figures 3-5) [8].

Aerosols are solutions or suspensions, where the active ingredient (in a liquid or solid- state) is suspended in a carrier gas, intending to deliver the drug to the alveoli. Nebulizers can transform the solution or suspension into small droplets based on different working mechanisms (jet, ultrasonic and mesh). They consist of a medication reservoir, a baffle compressor, a mouthpiece and a facemask. The general disadvantages of nebulizers are the high cost, difficulty in cleaning the device and the fact that drug wastage could occur. Moreover, electricity is necessary for the ultrasonic devices. On the other hand, they are easy to use, the contamination could be reduced, and they are more efficient when it comes to delivering active ingredients which cannot be delivered with the other devices.

Pressurized metered dose inhalers ( $p M D I s$ ) are the most frequently prescribed devices for asthmatic or COPD patients. Single-dose and multi-dose devices are accessible on the market, consisting of drug concentrate, propellant, metering valve and actuator. The main benefit of pMDIs is that the aerosol is formed by atomizing the extremely volatile propellant which is used to deliver an exact dose within a short treatment time. They are small and portable with a dose counter; therefore the patient can easily follow the therapy. 


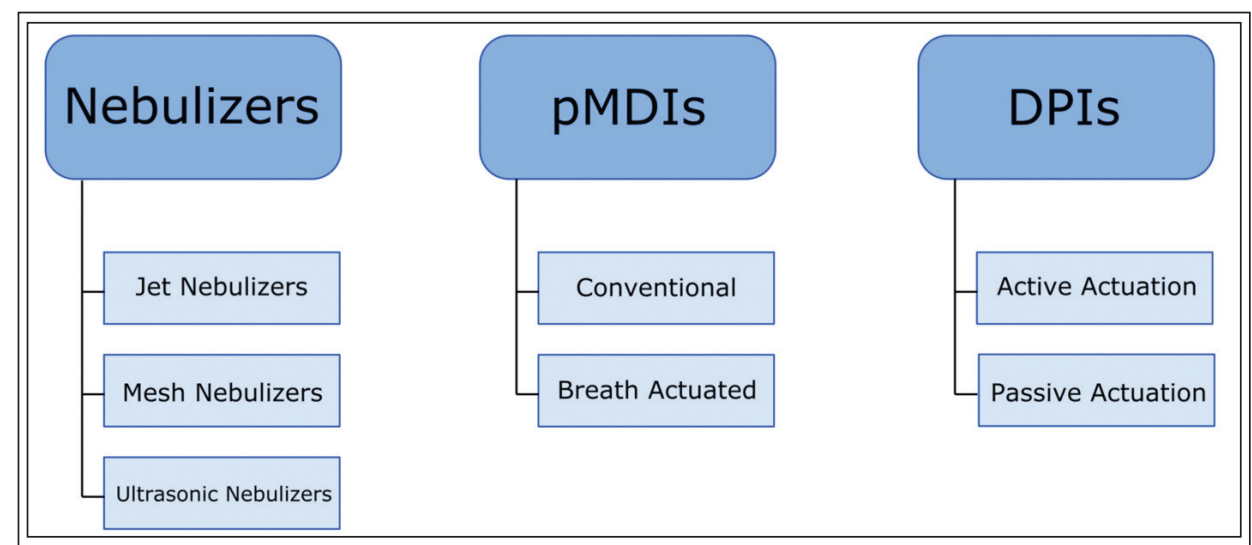

Figure 3 Types of inhalation devices

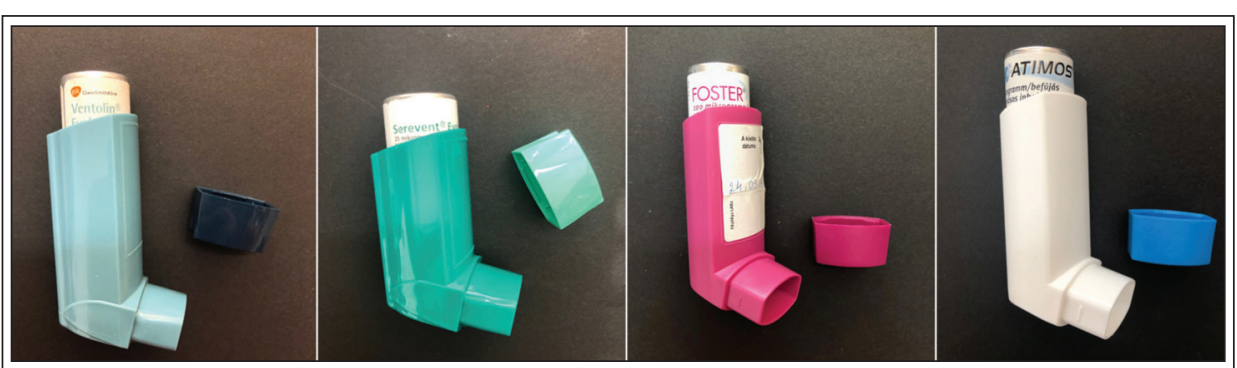

Figure 4 Examples of conventional pMDIs: Ventolin Evohaler, Serevent Evohaler, Foster, and Atimos

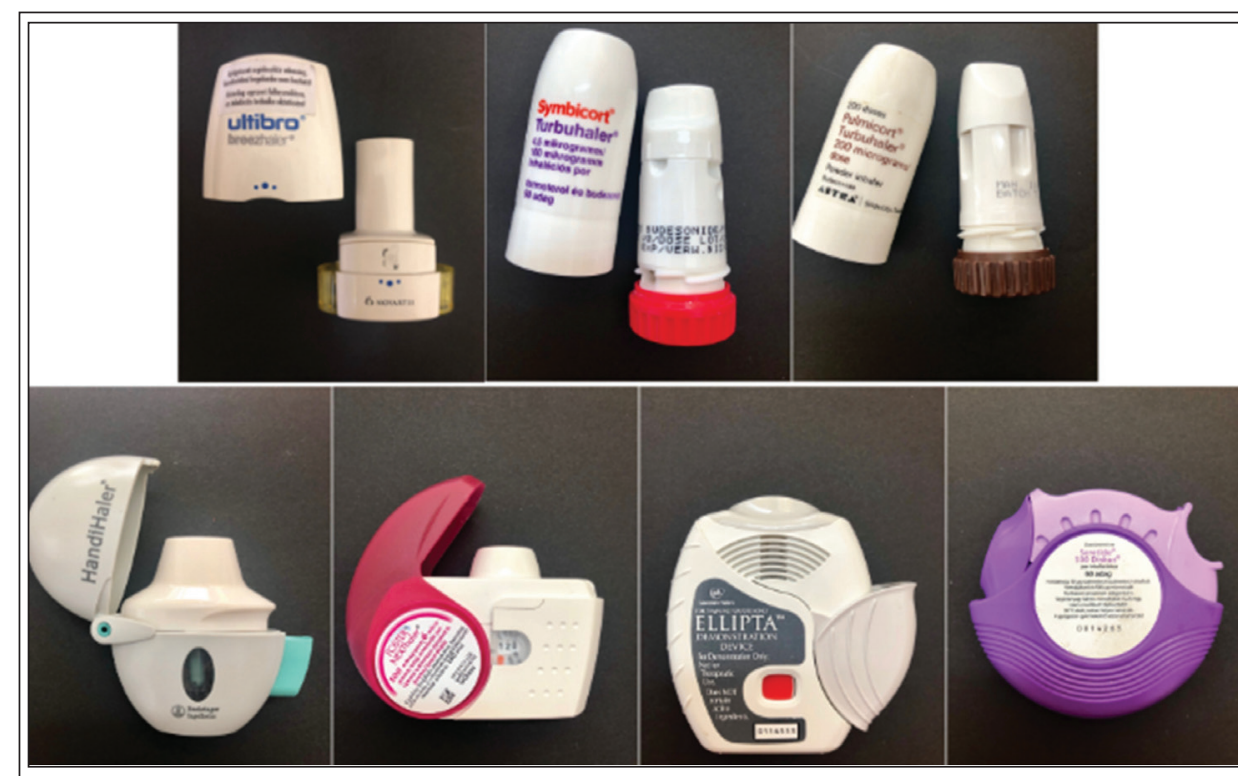

Figure 5 Examples of passive DPIs: Breezhaler, Symbicort Turbuhaler, Pulmicort Turbuhaler, Handihaler, Foster Nexthaler, Ellipta, and Seretide Diskus

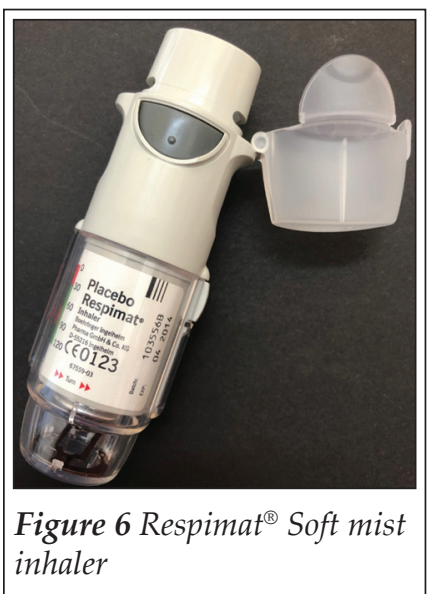

zle using a mechanical force. An example of that is the Respimat ${ }^{\circledR}$ SMI (Figure 6), which functions by using the mechanical energy of a string compressed by the patient $[11,12]$.

Another example of SMIs is the AERx Essence $^{\circledR}$ (Aradigm Corp.) which uses a breath-actuated piston system to push the solution through a nozzle arrangement, and a heating system to decrease the droplet size. A small screen incorporated to the device provides visual feedback to the patient. AERx Essence $^{\circledR}$ is used for the pulmonary administration of insulin [12-14].

Dry powder inhalers (DPIs) are propellant-free devices, containing fractionated and a micronized powder formulation of drugs. When a patient uses their inhaler, their in-
Soft Mist inhalers (SMIs) are MDIs, which are propellant-free. In order to produce an inspirable aerosol from a solution, the liquid dose needs to have a suitable droplet size. This can be achieved through two main methods: a first approach is the use of vibrations created by electrical energy (ultrasonic and piezoelectric devices). Another method would be pushing the solution through a noz- spiratory airflow constitutes the principal driving force for delivering breathable particles in dry powder to the deep lung. DPI devices contain the powder formulation, a dose-measuring system and a mouthpiece. The main advantages are that they are propellant-free, portable and require a short treatment time. However, the main disadvantages could be the dependence on the inspira- 
tory flow of the patient and the particle aggregation due to humidity $[8,10]$. A study using an invitro-in-silico procedure was performed on several DPI formulations placed in a highly humid environment. This study examined how these DPI formulations could influence a treatment when placed in a high humidity environment, alongside patients' wrong storage of the inhalers. The DPIs used were Easyhaler ${ }^{\circledR}$ and Novolizer ${ }^{\circledR}$, both containing budesonide and lactose. It concluded that formulations with smaller particle size and a higher quantity of excipient fines are more likely to be sensitive to humidity, which makes their efficiency inconstant after their storage [15]. This is particularly pertinent and problematic, considering that a significant amount of patients store their inhalers in unsuitable and highly humid conditions [16]:

- $42 \%$ of patients store their inhaler in a bathroom

- $21 \%$ in their pocket or a handbag

Concerning patients' errors, there are current trends which aim to face this challenge, such as smart devices. These devices are developed using electronic monitoring systems that can connect to other devices or even to an internet network. The goal is to decrease the errors made by both the patients and the devices, as well as to enhance the patients' compliance with inhalation therapy. These devices possess the ability to track the patients' adherence, as well as their use of the inhaler. The set goals are reached through characteristics such as a reminder which prompts the patient to take the dose, or even by providing the patient with a guide displayed on the inhaler's screen explaining the use of the inhaler step by step [17]. There are two different types of smart inhalers: "add-on" devices and "originally integrated" devices. An example of the originally integrated devices is the $3 \mathrm{M}^{\mathrm{TM}}$ Intelligent Control Inhaler by $3 \mathrm{M}^{\mathrm{TM}}$ Drug Delivery Systems [18].

\section{Appropriate inhaler use and supplementary devices}

Managing respiratory conditions such as asthma and COPD depends significantly on the proper use of the inhaler provided for the therapy. Incorrect use of the device or a faulty inhalation routine can reduce the drug delivery and therefore affect the disease control. A study conducted in France by Molimard et al. showed that out of over 3800 outpatients, $76 \%$ made a least one mistake while using a pMDI [19].
Even with the vast choice of devices available on the market and their level of precision, delivering an accurate dose can still be challenging sometimes. Moreover, when incorrectly using a pMDI, a poor drug deposition in the lungs occurs, resulting in a high oropharyngeal drug deposition [2022]. Consequently, spacers (also referred to as holding chambers or extension devices) can be used. Spacers are supplementary devices which improve the performance of an inhaler. They work by keeping the medication in an enclosed space during the inhalation. The use of a spacer added to a satisfactory inhalation technique can improve the drug delivery by up to $5-10 \%$ [23]. A study organized in India showed that out of 300 patients, $247(82.3 \%)$ made a mistake while using their inhaler. Out of these 247 patients, the highest number of errors was noted in patients using MDIs (94.3\%). However, patients who used a spacer with their MDIs resulted in a smaller percentage $(78 \%)$. Some of those errors were: "Inhaler not shaken" (40\%), "Long delay before inhalation" $(36 \%)$, and "Stopping inhalation as the device is fired" (32\%) [24]. Thus, spacers not only reduce oropharyngeal deposition, but they also decrease the accuracy demand for the actuation and inhalation while using a pMDI on its own [25]. This is particularly advantageous in infants and children since they are unable to produce an accurate inspiratory manoeuvre or refuse to cooperate. It is also recommended to use facemasks, especially in infants [22, 23]. Moreover, the use of spacers and facemasks is also helpful and convenient for patients who require medical assistance, such as elderly patients with COPD and cognitive impairment $[25,26]$. It has to be noted that spacers and facemasks are likely to be exposed to contamination by microorganisms. Since they are exposed and get in contact with mucous membranes, it is recommended they undergo cleaning, disinfection, rinsing, and air-drying after each use [27]. However, this cleaning procedure required after each use is not executed nor supported or endorsed by the manufacturers and the instructions leaflets they provide. Even so, it is advisable, at the very least, not to share spacers between patients [28].

In veterinary medicine, - proper use of spacers and facemasks can be observed to improve the therapy by optimizing the actuation. Since animal and human facial characteristics are not similar, a facemask constitutes an essential junction between the animal and inhalers such as nebulizers or 


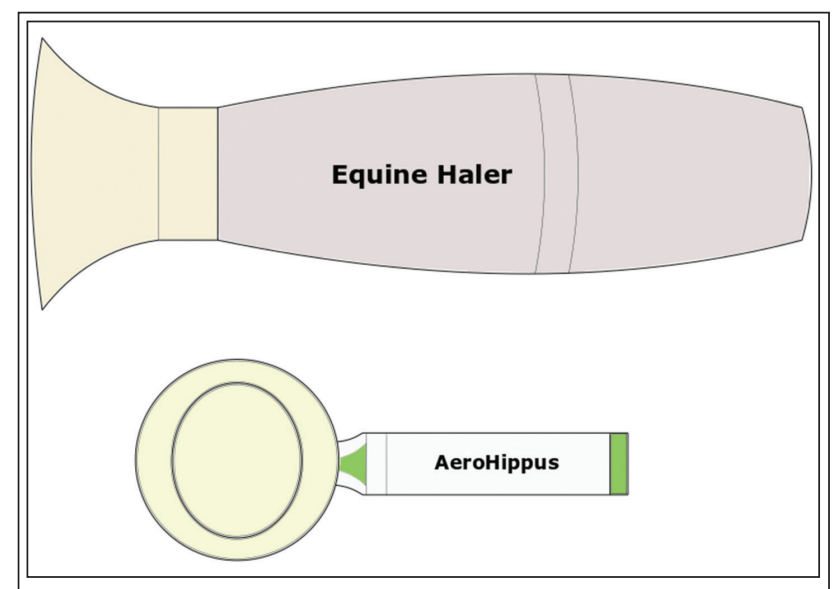

Figure 7 Sketches of the veterinary Equine Haler and AeroHippus devices

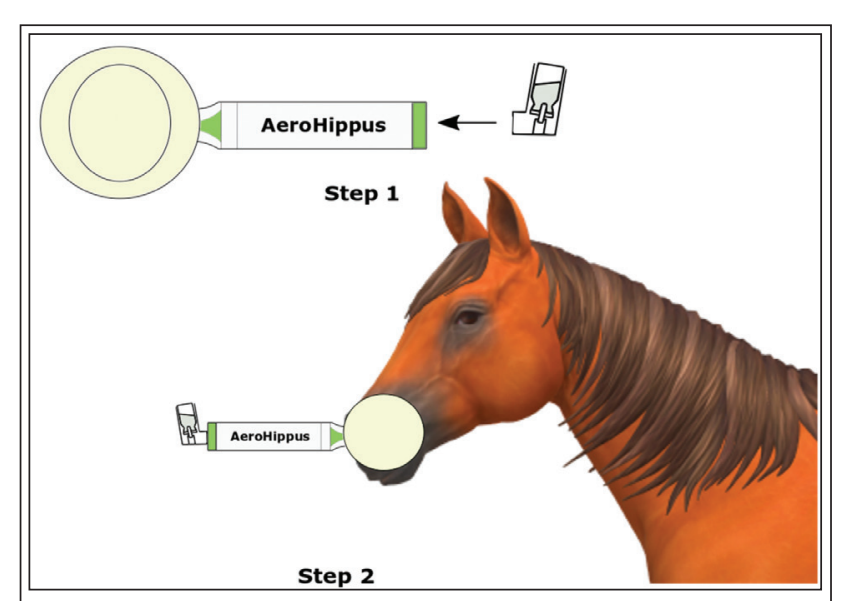

Figure 8 Inhaling mask for horses

pMDIs [29]. Moreover, contrary to humans, it is quite troublesome to control the breathing pattern of animals. In horses, for example, it is inconceivable to inquire a voluntary deep breath. Using an extension device such as spacers and facemasks allows the adaptation of commercially available human pMDIs to horses. Nebulizers could also be used, but unlike pMDIs with spacers, nebulizers permit the deposition of only small amounts of a drug in the equine lungs. In this regard, the utilization of pMDIs with a spacer in the veterinary practice is thought to be a great advance [30]. In case the horse reacts to the sound of the pMDI's actua- tion, there is a possibility for the inhaler to be actuated in the spacer, away from the horse's face. The chamber can then be placed on the horse's face, held up to the nostril, until the next inhalation. Examples of inhaling devices used for horses are Equine Haler and AeroHippus. (Figures 7 and 8) [30].

\section{Inhalation as an alternative delivery route}

\subsection{Prospects and innovative developments}

Inhalation as a delivery route finds its pertinence in the advantageous properties of the lungs (high permeability, large surface area). Moreover, an elevated local drug concentration can be obtained through pulmonary delivery, which is then rapidly absorbed through the alveoli, thus allowing a fast onset of action while at the same time still keeping systemic adverse effects to the minimum. The use of inhalation prevents specific gastrointestinal issues such as food effects, gut irritability, undesired metabolites, and poor solubility [31]. Furthermore, due to the absence of the first-pass metabolism, inhalation constitutes a great alternative to drug formulations, which cannot be delivered orally [32]. In addition, it also represents an excellent substitute for drug formulations, which are administered through an invasive method. Numerous macromolecules present in different stages of clinical development are listed in Table I. Similarly, examples of various small molecule inhalation products present in clinical development are listed in Table II [33].

There is also a possibility for vaccination through pulmonary delivery. Back in 1958 already, the possibility of vaccination via inhalation was suspected: a quite small number of living attenuated Mycobacterium tuberculosis (fewer than 25 infective units per animal) effectively induced immunity against airborne infection with virulent bacilli in guinea pigs [34].

Another example of this is Spiros ${ }^{\circledast}$ (developed by Dura Pharmaceuticals Inc.), a measles vaccine which is administrable using a DPI. Regrettably, it

Table I Examples of macromolecules in clinical development (based on [33])

\begin{tabular}{c|c}
\hline Macromolecule(s) & Targeted condition \\
\hline GLP-1 and insulin & Type 2 diabetes \\
\hline PTH (parathyroid hormone) and salmon calcitonin & Osteoporosis \\
\hline Erythropoeitin & Anemia \\
\hline Interferons & Multiple sclerosis \\
\hline Growth hormone $(\mathrm{GH})$ & Growth deficiencies \\
\hline Plasmid complex gene delivery & Hemophilia \\
\hline
\end{tabular}


Table II Examples of small molecules in clinical development (based on [33])

\begin{tabular}{c|c}
\hline Small molecule & Targeted condition \\
\hline Dihydroergotamine & Migraine \\
\hline Fentanyl citrate & Breakthrough pain in cancer \\
\hline Apomorphine & Male and female sexual diseases \\
\hline Nicotine & Smoking cessation \\
\hline
\end{tabular}

was not successfully marketed. One of its weaknesses was that in case of flat batteries, it was prone to failure. Besides, the intricacy of the device led to its expensiveness [1, 35].

A liposomal inhalation formulation has also been developed and FDA-approved for Amikacin, an aminoglycoside antibacterial drug. Arikayce ${ }^{\circledR}$ (ALIS - Amikacin liposome inhalation suspension) is a suspension administered once daily using the Lamira ${ }^{\mathrm{TM}}$ Nebulizer System. Amikacin is encapsulated in small liposomes (with a diameter of approximately $300 \mathrm{~nm}$ ) containing dipalmitoylphosphatidylcholine (DPPC) and cholesterol in a high drug-to-lipid ratio. It is used for the treatment of MAC (Mycobacterium avium complex) lung disease in a combination treatment for patients for whom the standard therapy has not been successful and whose substitute therapies are limited or unavailable. It has been shown that ALIS considerably improved the chances of obtaining sputum culture conversion when used as an add-on to guidelines-based therapy (GBT) compared to the use of GBT alone [36, 37].

\subsection{Insulin administration through pulmonary delivery}

Since the discovery of insulin in 1921-1922 at the University of Toronto [38], there has been a permanent search for a non-injectable yet effective route of administration. In 1987, a study was conducted on six diabetic children where semi-synthetic human insulin was administered via the pulmonary route using a nebulizer. The conclusion was that the blood glucose control gathered was at least as satisfactory as the one obtained following the administration of the regular dose of subcutaneous insulin [39]. Nevertheless, it was acknowledged that inhaled insulin had a considerably reduced bioavailability compared to that of the subcutaneous insulin. Thus, inhaled insulin reached clinical studies only after the delivery devices available, and particle pharmacology reached a certain advancement [40].

The oral and the nasal routes have been the most researched, but none of them ended up in a sustainable product due to the low and inconstant bioavailability. These issues are mostly due to the impermeability of the nasal and gastrointestinal epithelia to insulin. This unsuccessfulness led to the investigation of the pulmonary route since the lungs are naturally permeable to some proteins [41].

Fourteen short studies conducted on both healthy and diabetic patients investigated inhaled regular, soluble insulin as early as in 1925. Additionally, in all studies, a decrease in blood glucose was noted, as well as a considerable absorption of insulin. These events were obtained without the help of penetration enhancers. Moreover, despite early studies apprehensions concerning variable dosing, it has been guaranteed that the inhaled insulin's variability can be equally as good, if not higher than the subcutaneously injected insulin [41].

An example of inhalation insulin was Exubera ${ }^{\circledR}$ (developed by Pfizer Inc.). It was approved by both the FDA (Food and Drug Administration) and the EMEA (European Medicines Agency) for the treatment of type 1 and type 2 diabetes. It was a DPI which operated using blisters of $1 \mathrm{mg}$ or 3 $\mathrm{mg}$ of regular human insulin [40]. The greater part of the formulation was insulin (about 60\%). The excipients present consisted mainly of a stabilizer (mannitol) [42]. The device consisted of active powder dispersion by pressurized air obtained from a hand piston. Unfortunately, it has not been successfully marketed due to its cost, but also its significant number of operational steps required, and its large size. Insulin requires several administrations, notably in public. Therefore it is highly required for the device used to be convenient and discreet [1, 43]. In 2007, weak sales and poor acceptance of the inhaler prompted Pfizer to discontinue the diabetes drug $[6,40]$.

A new inhaled insulin example is Afrezza ${ }^{\circledR}$, an FDA-approved ultra-rapid acting insulin aiming to enhance postprandial glycemic control in diabetic patients, inhaled using a DreamBoat ${ }^{\mathrm{TM}}$ inhaler [44]. The administration of Afrezza ${ }^{\circledR}$ is ensured to be secure and effective in type 1 diabetic patients [45]. 
Table III Deposition mechanisms in the lung (based on [9])

\begin{tabular}{c|c|c}
\hline Particle size & Mechanism & Parts of Respiratory tract \\
\hline Above $5 \mu \mathrm{m}$ & Inertial impaction & Oropharynx and conducting airways \\
\hline $0.5-5 \mu \mathrm{m}$ & Sedimentation & Bronchi, Bronchioles and Alveoli \\
\hline $0.5-3 \mu \mathrm{m}$ & Sedimentation and Diffusion & Alveolar region \\
\hline Below $0.5 \mu \mathrm{m}$ & Diffusion and Brownian motion & \\
\hline
\end{tabular}

\section{Drug deposition and absorption in the lungs}

Particle deposition is the first step after inhalation. It can occur in the lungs by three main mechanisms: inertial impaction, sedimentation and diffusion. Other mechanisms are an interception and electrostatic precipitation which are related to the particle shape and the electrostatic charges $[9,46]$. The deposition mechanisms in the lungs are demonstrated in Table III.

Inertial impaction is the principle deposition mechanism in the 1-10 generations of the lungs due to the elevated air velocity with the turbulent flow. Larger molecules (above $5 \mu \mathrm{m}$ ) tend to move out with the air stream and impact the wall of the upper airways. The properties of particles, such as density and diameter play a significant role in this case.

Sedimentation is the time-dependent effect on the particles with 0.5-5 $\mu \mathrm{m}$ size in the deeper lung (bronchi, bronchioles and alveolar region) where the velocity decreases. The gravitational force causes the deposition of the particles and is derived by particle diameter, mass, residence time and decreased flow rate. Particles of 3-5 $\mu \mathrm{m}$ reach the tracheobronchial region with sedimentation. Sedimentation and diffusion are expected in case of particles with a size of $0.5-3 \mu \mathrm{m}$ which are able to reach the alveolar region.

In the alveolar region, particles with a size smaller than $0.5 \mu \mathrm{m}$ will deposit according to the diffusion principle due to the Brownian motion. Nevertheless, due to their significantly small size, the majority of the particles are exhaled and merely few of them deposit.

Direct interception is a phenomenon which usually occurs in case of particles with elongated shape in the upper airways, while charged particles are prone to undergo electrostatic deposition [9].

The fate of particles after inhalation depends on the physiology of the patients and the aerosol properties of the particles, namely size, size distribution, shape, charge, density and hygroscopicity $[10,46]$. It is well established (Table III) that the size of particles has an important significance in the particle deposition. There are two main calcu- lable parameters which express the aerodynamic properties of aerosols: the mass median aerodynamic diameter (MMAD) and the geometric standard deviation (GSD). MMAD is a diameter which is calculated based on the mass distribution and divides particles into two parts: $50 \%$ of the aerosol is larger, the remaining $50 \%$ is smaller. If the MMAD is between $0.5 \mu \mathrm{m}$ and $5 \mu \mathrm{m}$, the aerosol is usually considered breathable. The ideal size for a deep lung deposition is 2-3 $\mu \mathrm{m}$. The GSD demonstrates the variance within the particles, in which the values of 1 and above 1.2 indicate mono-disperse and hetero-disperse systems [10]. Spherical-shaped particles are the most preferred and could easily be manufactured. However, elongated particles are gaining attention due to the lung penetration of fibers. Generally, low-density particles with a large geometric diameter have better aerodynamic properties than high-density particles with a small geometric diameter [10]. There are strategies to alter the aerodynamic diameter $\left(D_{\text {ae }}\right)$. These are based on the following equation (1), where $D_{\text {eq }}$ is the diameter of an equivalent volume sphere of unit density, $\varrho_{p}$ and $\mathrm{Q}_{\mathrm{o}}$ are particle and unit densities, and $\mathrm{X}$ is the dynamic shape factor [47]:

$$
D_{a e}=D_{e q} \sqrt{\left(\frac{\rho_{p}}{\rho_{o} X}\right)}
$$

Both large and porous or needle-shaped particles are presumed to have a smaller aerodynamic diameter than their particle size would suggest [47]. All of these parameters aside, the surface charge and the hygroscopicity are also important physicochemical properties. While the surface charge of the cell membrane is negative, small particles with a positive charge can bind easily. However, the mucus layer of the lung epithelium acts as an absorption barrier due to its adhesive surface; therefore it may hinder the penetration of even charged particles [48]. Hygroscopic materials should be formulated carefully in case of DPIs due to the proneness to aggregation [46]. 
Drug absorption in the lung is also influenced by the physiological environment and clearance mechanisms. In the human lung, the dissolving medium volume is about $10-30 \mathrm{ml}$ with a $\mathrm{pH}$ of about 6.6 and consists of $96 \%$ water. The remaining $4 \%$ are electrolytes and proteins. The drug particles should be in a dissolved state in order to absorb, otherwise they might get cleared up by one of the clearance mechanisms. The principal clearance mechanism is the mucociliary clearance (MCC) which is derived by the synchronous sweeping movement of cilia and mucus on the surface of epithelial cells. Their function is the removal of particles from the environment. Therefore, with the propulsive movement of mucus towards the larynx, the particles will be eliminated by swallowing or coughing out, generally within 24 hours. The other possibility is the alveolar clearance which is a defence mechanism against harmful microorganisms and particles by macrophages. Particles with a size between $1.5 \mu \mathrm{m}$ and $3 \mu \mathrm{m}$ are more susceptible to phagocytosis, and the alveolar permeability is decreasing with increasing molecular weight. There is also a mechanical clearance for large particles (above $10 \mu \mathrm{m}$ ) which immediately induces coughing, sneezing or swallowing [9]. The metabolisms in the lungs are similar to the liver. All of phase I metabolizing enzymes can be found in the lung, however, in lower quantities and CYP3A5 is expressed abundantly in the lungs [9].

Figure 9 shows the correlation between the aerodynamic diameter (in $\mu \mathrm{m}$ ) and the percentage of deposition in the lungs. The aerodynamic diameter

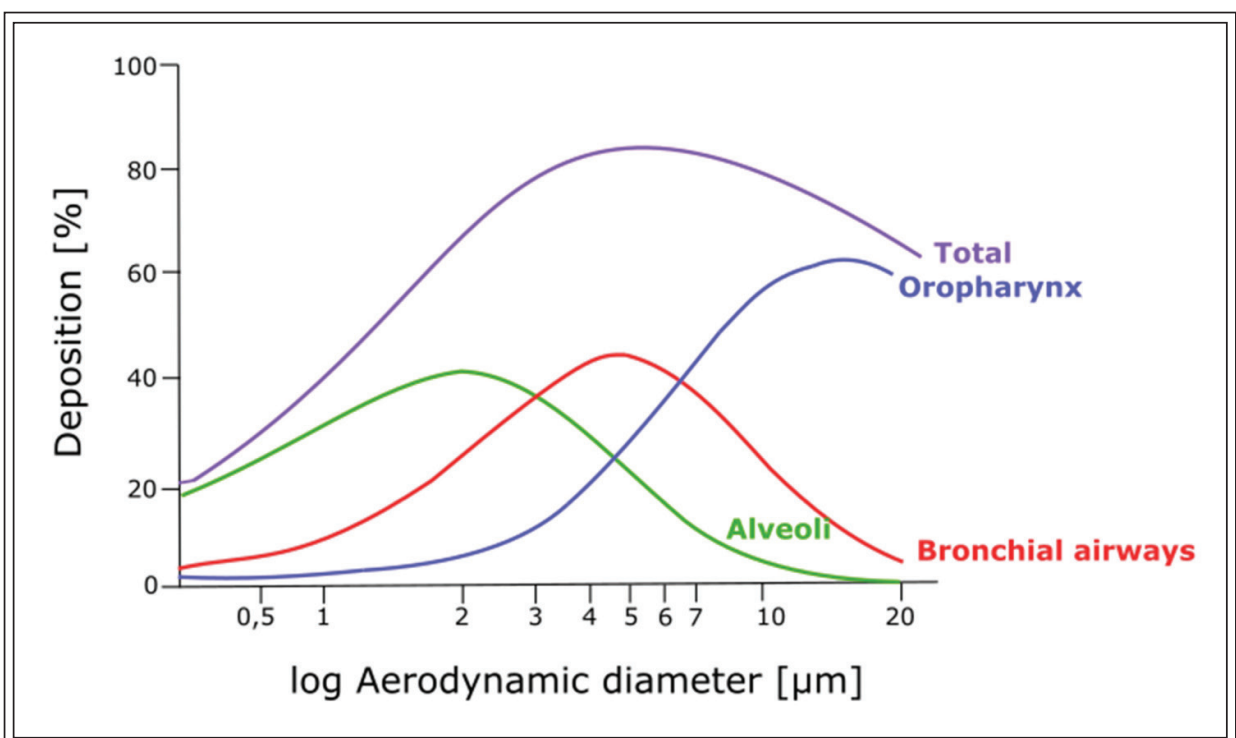

Figure 9 Relationship between particle aerodynamic diameter and lung deposition (based on [49]) is the diameter of a sphere with the same settling velocity as the particle of interest [50]. As mentioned before, large molecules with an aerodynamic diameter higher than $5 \mu \mathrm{m}$ tend to impact on the wall of the upper airways and get swallowed. Therefore, the particles with an aerodynamic diameter smaller than $5 \mu \mathrm{m}$ are the ones with the highest potential for deposition in the lungs. In an aerosol, the ratio of these particles is referred to as either the fine particle dose (FPD) if it is expressed in absolute mass of drug in the particles that are smaller than $5 \mu \mathrm{m}$, or the fine particle fraction (FPF):

- The FPD is the mass of particles smaller than 5 $\mu \mathrm{m}$ present within the total emitted dose.

- The FPF is equal to the FPD divided by the total emitted dose.

The higher is the FPF in an aerosol, the higher is the probability of it depositing deeper in the lungs. Consequently, present inhaler devices produce aerosols containing a considerable percentage of particles between 1 and $5 \mu \mathrm{m}$ [49].

\section{Formulation of inhalation dosage forms}

\subsection{Excipients in the pulmonary drug delivery}

The International Pharmaceutical Excipients Council (IPEC) characterizes excipients as substances in a pharmaceutical formulation other than the active pharmaceutical ingredients which "have been appropriately evaluated for the safety in order to help processing, manufacturing, protection, and give support or to enhance stability, bioavailability, or patient acceptability or to assist in product identification or improve any features of the safety or effectiveness of the drug delivery system during storage or use." [51]. When it comes to pulmonary drug delivery, excipients are particularly necessary in the formulation in order to achieve an optimal size, for instance. As a consequence, excipients for inhaled drugs are usually present in relatively high amounts compared to the active pharmaceutical ingredient. 


\subsection{Formulations in the pulmonary drug delivery}

As seen previously, the inhalation systems can be divided into three main types: nebulizers, pMDIs, and DPIs.

Nebulizers' formulation consists of sterile water combined with co-solvents if needed. It is preferable to keep the number of excipients present in the formulation to a minimum in order to avoid toxicity [9].

The formulation of pMDIs consists of a product concentrate, which will be either solubilized or dispersed in a propellant using an elevated vapour pressure. The formulation itself is quite complex, owing to the presence of both propellants and high vapour pressure [9]. Propellants can be liquefied compressed gas, compressed gas propellants, or chlorofluorocarbons. However, due to their ozone-depleting behaviour, the use of chlorofluorocarbons has been discontinued since January $1^{\text {st }}, 1996$, following the Montreal Protocol. They since have been replaced by hydrofluoroalkanes [52].

Out of the three main types of inhalation systems, DPIs would be the most advantageous type due to their propellant-free formulation. However, DPIs' formulation requires the use of micronized drug particles. These particles display poor flow properties as well as cohesiveness. Increased Van der Waals, electrostatic forces, and surface tension between the layers of particles result from the high surface area to mass ratio caused by the micronized drug particles [9]. Because of this, their formulation usually requires the active pharmaceutical ingredient to be combined with coarse and fine carrier particles. This will, in turn, ameliorate the flow properties and raise the particle aerodynamic behaviour [53].

The particle size of an aerosol plays a crucial role in delivering the drug to its target site, hence providing an efficient therapy, while simultaneously avoiding clearance mechanisms [54]. In fact, in aerosol therapy, the particle size is believed to be one of the most crucial physical characteristic [30]. In horses for instance, similarly as in humans, particles which are considered to be large $(>10 \mu \mathrm{m})$ are either separated and filtered in the upper respiratory tract or collected in the larger airways. Particles which are considered to be mediumsized $(6-10 \mu \mathrm{m})$ will deposit and accumulate in the larynx, trachea, bronchi, and large diameter bronchioles. Particles which are considered to be small (5 $\mu \mathrm{m}$ or less) will deposit in the small-diameter bronchioles and alveoli; while roughly half of the particles which are considered to be very small $(<1 \mu \mathrm{m})$ will deposit in the alveoli, while the other half will be exhaled [30]. Therefore, powder formulations intended for inhalation generally contain micronized drug particles with a particle size between 1 and $5 \mu \mathrm{m}$ in order to obtain a valuable central and deep lung deposition. These drug particles are usually blended with an inactive excipient of greater size $(40 \mu \mathrm{m})$. Possible inactive excipients are: lactose, mannitol, trehalose, sucrose, sorbitol, and glucose [55]. Among them, lactose (precisely $\alpha$-lactose monohydrate) is the most frequently used carrier owing to its numerous advantageous properties such as [56]:

- Physico-chemical stability and compatibility (displayed with most low molecular weight drugs)

- Safe toxicological profile

- Availability and affordability

Nonetheless, lactose possesses disadvantages as well: it cannot be administered to patients who are diabetic or lactose-intolerant since it gets ultimately swallowed by the patient, due to its impact on the oropharynx following the device actuation [56]. Due to these reasons, mannitol can be used as an alternative to lactose [57]. It is also relevant to bear in mind that an active pharmaceutical ingredient containing amino groups (proteins, weak bases) cannot be present in the same formulation as reducing sugars because it would lead to instability due to the Maillard reaction [58]. In order to overcome this, non-reducing disaccharides, nonreducing polysaccharides (trehalose and raffinose, for instance), and other sugars are being investigated as carriers [56].

Moreover, several active pharmaceutical ingredients are highly potent: drugs used for the treatment of diseases such as asthma are already effective at a low dose. For instance, only 200-400 $\mu \mathrm{g}$ for salbutamol and 6-12 $\mu \mathrm{g}$ for formoterol are required for the drug to be effective [59]. This arises issues concerning powder handling as well as precise metering of doses. In order to overcome those issues, carriers can be used. The carrier material should meet requirements such as [56, 60]:

- Providing bulk and ensuring flowability

- Decreasing the agglomeration of the particles

- Facilitating powder handling and dosing by providing a larger volume to the formulation

- Helping the dispersion of the micronized drug

Moreover, fine lactose particles present within an equivalent size range as the active pharmaceu- 
tical ingredient have been identified as an important element in order to improve the formulation performance [61]. Among the possible explanations for this phenomenon are the presence of active sites and the agglomeration of drug and fine excipients [62]. Inhalation formulations containing a low dose of the active pharmaceutical ingredient tend to be more affected by the properties of the carrier. This might be due to the occurrence of active sites on the carrier as well as their availability [60]. The drug/lactose ratio and the aerosolization performance are correlated, and this correlation is associated with the possible existence of active sites on the surface of the lactose carrier [63].

\subsection{Carriers suitable for a small particle size}

Powders suitable for inhalation are most commonly obtained by carrier-based systems which consist of two elements: the drug and its carrier.

The drug is usually mixed with larger, coarser lactose particles which act as a carrier and ameliorate the dose reproducibility. As the drug and the carrier are blended, the micronized drug particles attach to the surface of the lactose carrier particles, hence forming an adhesive mixture (Figure 10).

Furthermore, interparticulate forces present in adhesive mixtures are required to be able to produce a blend which is stable and homogenous. Due to the considerable size difference between the drug and its carrier, the unplanned separation of the two should be avoided, while still enabling an easy detachment of one from the other through

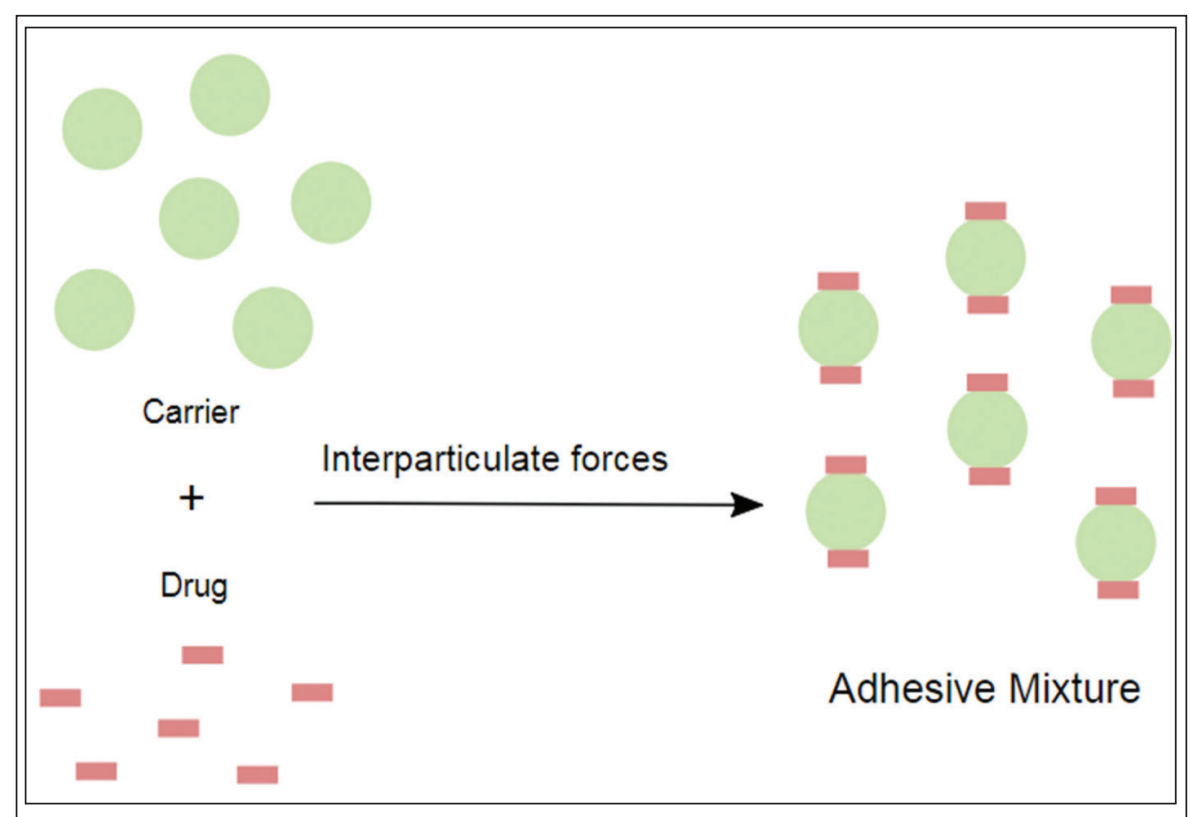

Figure 10 Adhesive mixture formation weak enough drug-carrier interactions. Consequently, the drug delivery occurs through three steps [56]: the detachment of the active pharmaceutical ingredient from its carrier, their dispersion in the airflow, and the deposition in the respiratory tract (Figure 11). In the case of DPIs, the powder formulation is present in the capsule in an aggregated form with a size of $100-150 \mu \mathrm{m}$. In order to disaggregate it, a deep and strong inhalation through the device is required, thus reducing it to inhalable particles $(1-5 \mu \mathrm{m})$ which can successfully deposit in the lungs [64]. This de-aggregation process constitutes a fundamental requirement for DPIs capsules contents [65].

During the drug/carrier detachment in the first step, the fate of the carrier is either to remain in the inhalation device or to deposit in the oropharyngeal region. In adhesive drug mixtures, excipients used as carriers are considered to have a "limited" loading capacity, which makes them convenient for low drug doses. Classic drug-tocarrier ratios are $1: 67.5$ or 1:99 [56]. The drug quantity which can be processed is limited due to requirements for the content uniformity and stability [66]. The limit is set to $5-10 \%$ of the drug, depending on the excipient used in the formulation as a carrier [67].

The use of active pharmaceutical ingredients at a low dose such as dry powders is mainly aimed for the therapy of respiratory diseases (asthma, COPD). In pulmonary drug delivery, the dose of a drug used is considered low when it is in the microgram range $(<1 \mathrm{mg})$ [66]. The drug dose can vary from $6 \mu \mathrm{g}$ (eformoterol fumarate: Oxis $\left.{ }^{\circledR}\right)$ to $500 \mu \mathrm{g}$ (fluticasone propionate: Flixotide $^{\circledR}$, Seretide ${ }^{\circledR}$ ) [68].

\section{Tests and characterization of aerosols}

\subsection{Tests}

As seen previously, the formulation of inhalation dosage forms plays a great role in their efficiency and is therefore quite elaborated. The processes it involves are complex; thus thorough testing is necessary to ensure the safety and quality of the end product. Table IV displays the gen- 


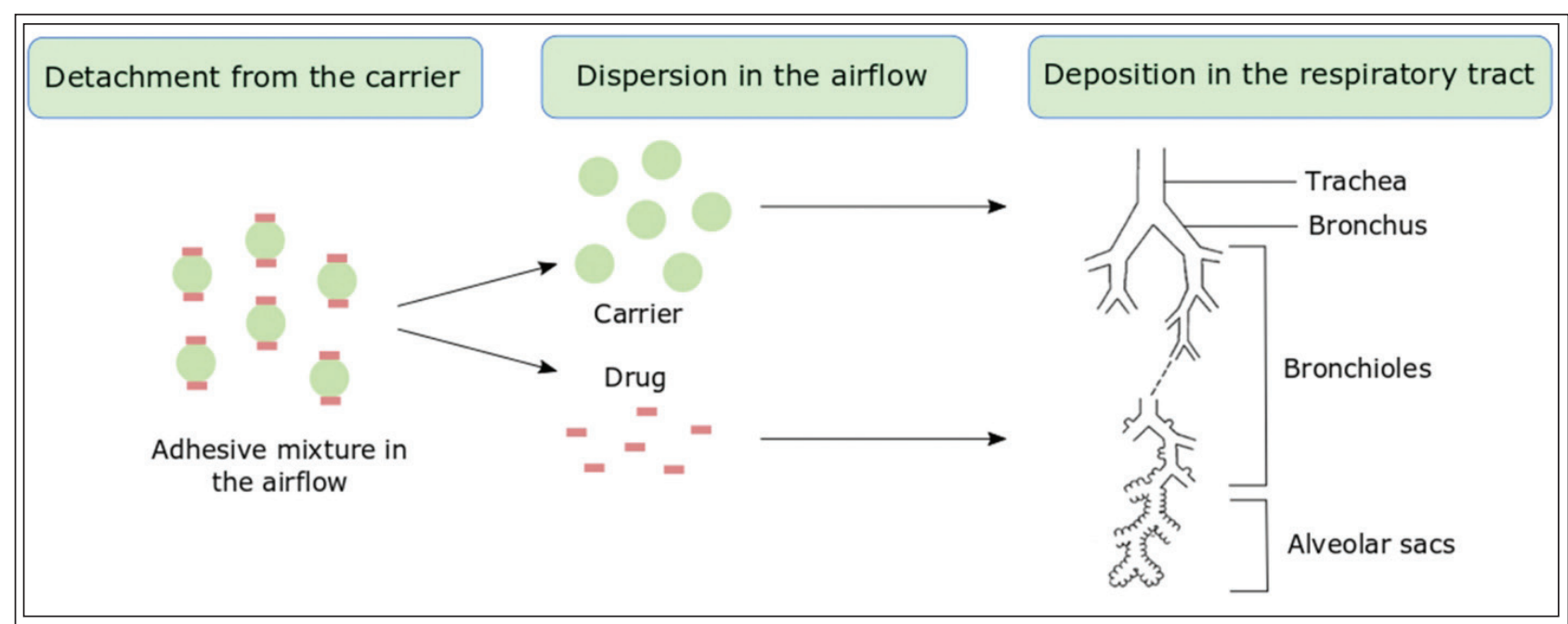

Figure 11 Illustration of the steps in the drug delivery of carrier-based formulations

Table IV Aerosol devices and formulations tests (based on [9, 69])

\begin{tabular}{|c|c|}
\hline Test & Description \\
\hline Dose uniformity & $\begin{array}{l}\text { - Assay of the material or the solvent onto which the dose is sprayed. } \\
\text { - Firstly, an empty container is weighed. Secondly, a certain number of doses are sprayed in this } \\
\text { same container, which is then weighed again. The difference in weight is then calculated, and } \\
\text { divided by the number of doses sprayed. }\end{array}$ \\
\hline $\begin{array}{c}\text { Particle size } \\
\text { determination }\end{array}$ & $\begin{array}{l}\text { The determination is done using a cascade impactor or using a light scattering decay method. } \\
\text { The particle size is expressed in } \mu \mathrm{m} \text {. }\end{array}$ \\
\hline Moisture content & $\begin{array}{l}\text { The test can be done by Karl-Fischer or by gas chromatography. The moisture content is ex- } \\
\text { pressed in } \% \text {. }\end{array}$ \\
\hline Density & $\begin{array}{l}\text { The test can be done using a hydrometer or a pycnometer. A pressure tube is fitted with a Hoke } \\
\text { valve, metal fingers, and a hydrometer placed into it. The sample is then put in through the Hoke } \\
\text { valve. This causes the hydrometer to elevate in the pressure tube at half height. The density can } \\
\text { then be read and is expressed in } \mathrm{g} / \mathrm{ml} \text {. }\end{array}$ \\
\hline Vapor pressure & $\begin{array}{l}\text { The test can be done by pressure gauge. The pressure variation between containers indicates the } \\
\text { presence of air in the headspace. Vapor pressure can also be accurately measured using a can } \\
\text { punctuating device. The vapor pressure is expressed as } \mathrm{kPa} \text {, bar, atm, or psi. }\end{array}$ \\
\hline Spray & $\begin{array}{l}\text { The aerosol being tested is sprayed on a paper coated with a dye-talc mixture. The dye is either } \\
\text { water-soluble or oil-soluble. Particles which collide with the coated paper cause the dye to solu- } \\
\text { bilize and get absorbed onto the paper. This gives a definite spray pattern. }\end{array}$ \\
\hline $\begin{array}{l}\text { Aerosol valve discharge } \\
\text { rate }\end{array}$ & $\begin{array}{l}\text { Two weights are measured: } \mathrm{W}_{1} \text { and } \mathrm{W}_{2} \text {. } \\
-\mathrm{W}_{1} \text { : Initial weight of a container } \\
-\mathrm{W}_{2} \text { : Weight of that same container after being actuated for a particular period of time. } \\
\text { The discharge rate with respect to time is obtained by dividing the difference in weights by the } \\
\text { time (of the actuation process). }\end{array}$ \\
\hline Propellant identification & $\begin{array}{l}\text { The identification can be done by gas chromatography or infrared spectrophotometry. These } \\
\text { methods can also be used to determine the composition of a blend of propellants. } \\
\text { The determination of moisture, halogen, and non-volatile residue provide an acceptability and } \\
\text { purity check of the propellants. }\end{array}$ \\
\hline $\begin{array}{l}\text { Flammability and } \\
\text { combustibility } \\
\text { (Flash Point) }\end{array}$ & $\begin{array}{l}\text { The test requires a Tag Open Cup (TOC) apparatus. The aerosol product is chilled to }-25^{\circ} \mathrm{F} \\
\left(=-31.67^{\circ} \mathrm{C}\right) \text { then transferred to the apparatus. The temperature of the liquid is gradually } \\
\text { increased. When the liquid's vapor ignites, the "flash point" temperature has been reached. It is } \\
\text { expressed in }{ }^{\circ} \mathrm{C} \text {. }\end{array}$ \\
\hline Flame projection & $\begin{array}{l}\text { The test measures the extension of a flame length when the aerosol product is sprayed on an open } \\
\text { flame for about } 4 \text { seconds. A ruler is used to measure the extension of the flame, and the result } \\
\text { is expressed in } \mathrm{cm} \text {. }\end{array}$ \\
\hline
\end{tabular}


eral and additional evaluation tests done on aerosols and their formulation $[9,69]$.

Characterization of the performance of DPIs can be done using two aspects: the patient's inspiratory flow and the turbulence generated inside the inhaler itself. Since DPIs are breath-actuated devices, the powder formulation they deliver requires the patient to supply turbulent inspiratory forces to break down the powder aggregates into fine particles of less than $5 \mu \mathrm{m}$ in diameter in order for them to deposit deeper in the lungs. As mentioned before, optimal use of the dry powder inhaling device is determined by the patient providing an appropriate inspiratory flow, and the turbulence generated by the intrinsic resistance of the inhaler, which is influenced by the design of the device. Basically, three varieties of designs are available, with a low (such as the Breezhaler ${ }^{\circledR}$ ), medium (such as the Ellipta ${ }^{\circledR}$ ), or high resistance (such as the Handihaler ${ }^{\circledR}$ ). The duplicability of the dose by the device at different flow rates demonstrates how the incorrect manipulation of the inhaler affects the system. The higher the inspiratory flow, the better the performance of the device since the drug dose inhaled by the patient is increased [70, 71]. A favourable peak inspiratory flow rate should be of minimum $60 \mathrm{~L} / \mathrm{min}$ through the inhaler to achieve disaggregation of the powder formulation. The device-specific airflow resistance is determined using the pressure drop and the flow rate following Ohm's law, as shown in equation (2) [72]. Higher airflow resistance is associated with more considerable difficulties for patients (particularly in children and elderly people) to adequately operate the device with an appropriate flow rate, which makes the airflow resistant a significant parameter [70].

$$
R=\frac{\Delta P}{Q}
$$

where $\mathrm{R}=$ Resistance, $\Delta \mathrm{P}=$ Pressure drop, $\mathrm{Q}=$ Flow rate.

Oxis Turbuhaler ${ }^{\circledR}$ and Foradil Aerolizer ${ }^{\circledR}$ DPIs have been tested in vitro to study their efficiency in delivering $12 \mu \mathrm{g}$ of Formoterol fumarate, a $\beta_{2}$-sympathomimetic drug, and $600 \mu \mathrm{g}$ of lactose monohydrate. Four flow rates were investigated (28.3, 40, 60, and $80 \mathrm{~L} / \mathrm{min}$ ). The optimum flow rate for both inhalers ranges between 40 and $60 \mathrm{~L} / \mathrm{min}$ to deliver a satisfactory bronchodilation effect. The study concluded that Oxis Turbuhaler ${ }^{\circledR}$ delivered smaller particles; thus a deeper lung deposition was achieved. However, the high specific airflow resistance is a factor which will affect the usage of the device by severe asthmatic children. Nevertheless, no difference in their bronchodilating effect was found [73].

\subsection{Particle size determination}

\subsubsection{Cascade Impactor}

The determination of the therapeutic activity of an inhalation aerosol is dependent on the particle size [69]. Cascade Impactors are mentioned in the Pharmacopeia and therefore constitute the most commonly used devices for the in vitro study and measurement of the particle size distribution of inhaled formulations. This is mainly due to their numerous advantages such as the direct measurement of aerodynamic particle size, and the determination of drug mass in the formulation with different size ranges, without the disturbances from the excipients [17].

Originally, the Andersen Cascade Impactor (ACI) was the most commonly used impactor in the pharmaceutical industry. However, the ACI displayed certain disadvantages and has since been replaced by the Next Generation Impactor (NGI), specially designed for inhaler testing [74] (Figure 12).

Cascade impactors rearrange particles and droplets in an aerosol based on their aerodynamic diameter. They use particle/droplet inertia impaction to segregate particles and droplets from a moving airstream [69]. The NGI comprises 7 stages (Figure 13), 5 of which are in a 0.5-5 microns range. Each stage contains a set of nozzles. The airflow moves

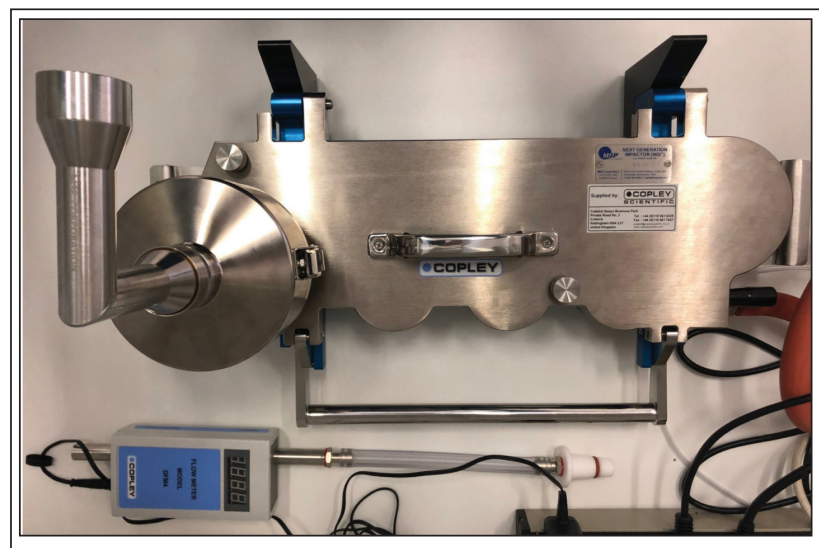

Figure 12 Next Generation Impactor (NGI) with induction port and preseparator 
across the apparatus following a sawtooth pattern. The velocity of the airstream is increased as it is forced to cross through a sequence of nozzles comprising progressively decreasing jet diameters. This results in particle separation as well as sizing [74].

Another particular feature of the NGI is also its microorifice collector (MOC). It catches highly small particles in a collection cup, which can be evaluated along with the particles collected in the stages cups [75]. Aerodynamic properties can be calculated from the collected data.

Figure 14 shows the Spiriva HandiHaler ${ }^{\circledast}$ placed on the induction port of the NGI. HandiHaler is an $18 \mu \mathrm{m} / \mathrm{cap}$ sule DPI made by Boehringer Ingelheim/Pfizer Inc. Its powder is delivered at a flow of 20-30 L/min, making it a flow-limiting device [77, 78].

Figure 15 demonstrates the Serevent Evohaler ${ }^{\circledR}$ placed on the induction port of the NGI. Serevent Evohaler is a $25 \mu \mathrm{m} /$ actuation inhaler made by GlaxoSmithKline Inc. It is a CFC-free pMDI [79].

\subsubsection{Laser Diffraction}

Particle size analysis can also be performed using optical methods as an alternative, such as laser diffraction (light scattering), laser Doppler, or time-of-flight. The most widely used among these is the laser diffraction [17]. The Cascade Impactor analysis can be substituted by laser diffraction in order to assess the particle size, however, aerodynamic diameters cannot be measured with this technique. Moreover, the main advantage offered by NGIs is the determination of the FPF and other size fractions. The other methods, such as laser diffraction provide no differentiation. It simply measures the overall particle size distribution in the sample [80]. However, laser diffraction is considered to be a remarkably accurate, flow rate-in-

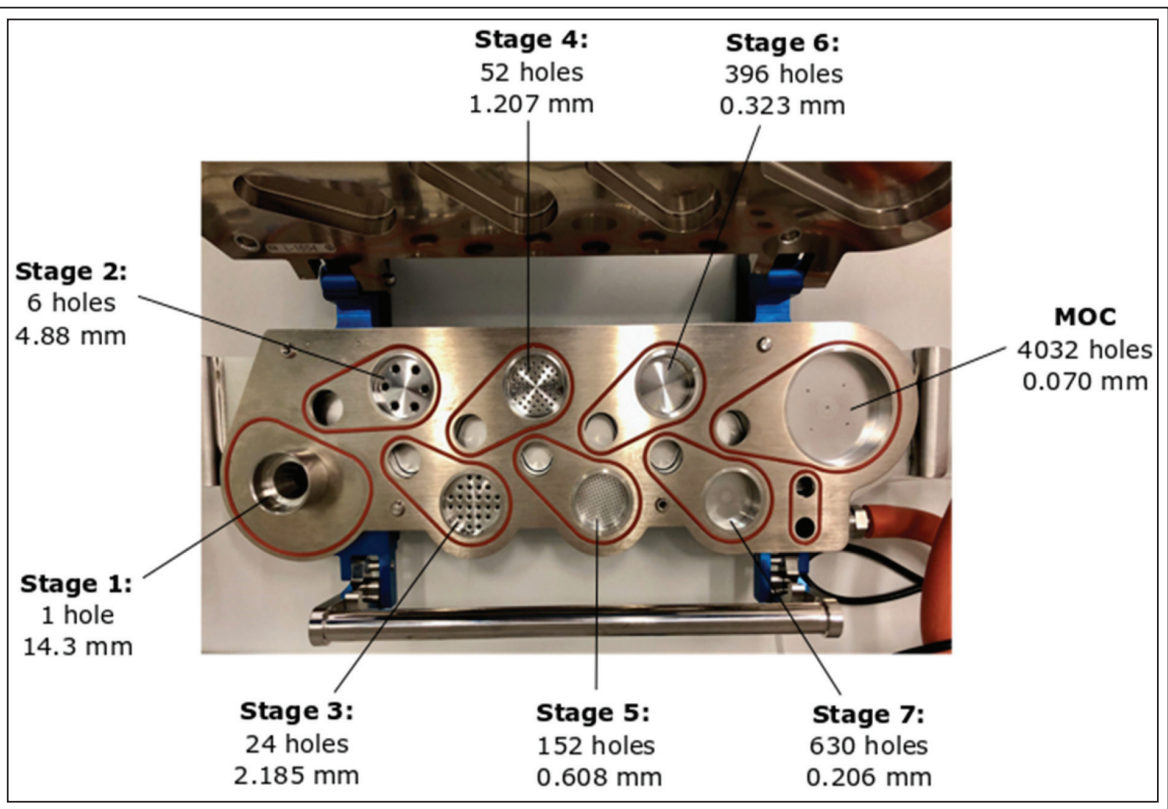

Figure 13 NGI stages and micro-orifice collector (MOC) with their number of holes and nozzle diameter (based on $[75,76]$ )

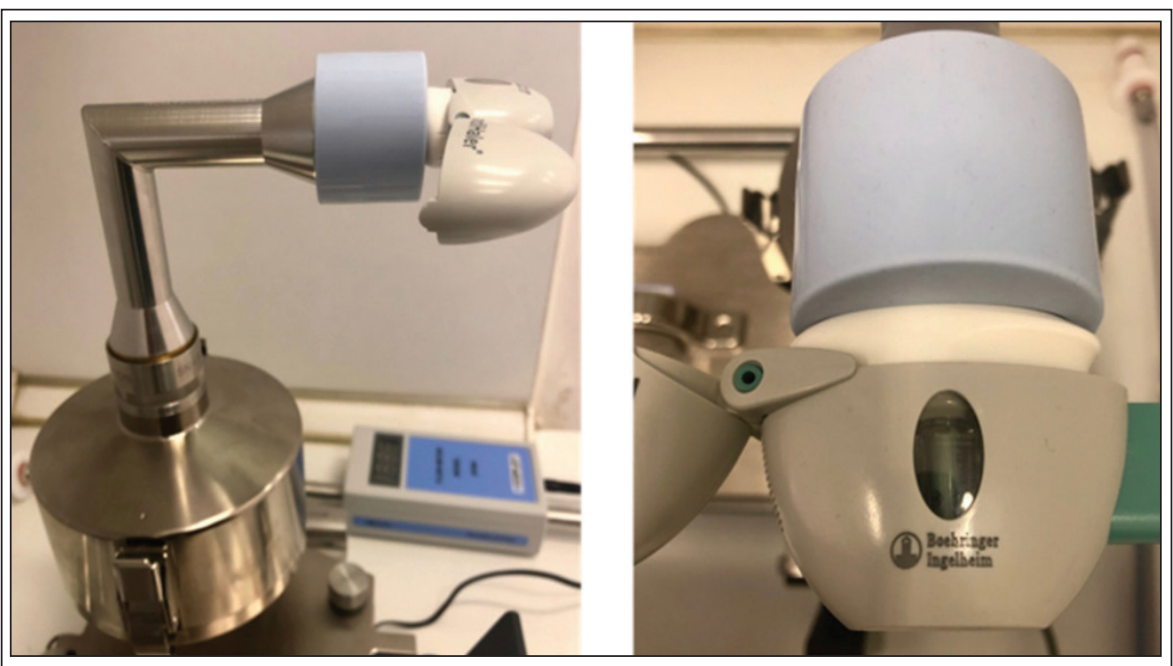

Figure 14 HandiHaler placed on the induction port of the NGI

dependent and a rather quick method and therefore constitutes an excellent alternative for the cascade impactor measurements. This technique has been used since the 1980s to measure the particle size of nebulized drug solutions [81].

The laser produces a monochromatic, coherent, parallel beam which is widened by the beam expander unit (Figure 16). This beam then casts a light on the dispersed particles. The light produced is scattered by the dispersed particles. These particles in the measuring zone form scattering patterns and these patterns carry information on the number of particles, the particle size, and the particle shape in any orientation $[82,83]$. Examples of laser diffraction instruments are: 


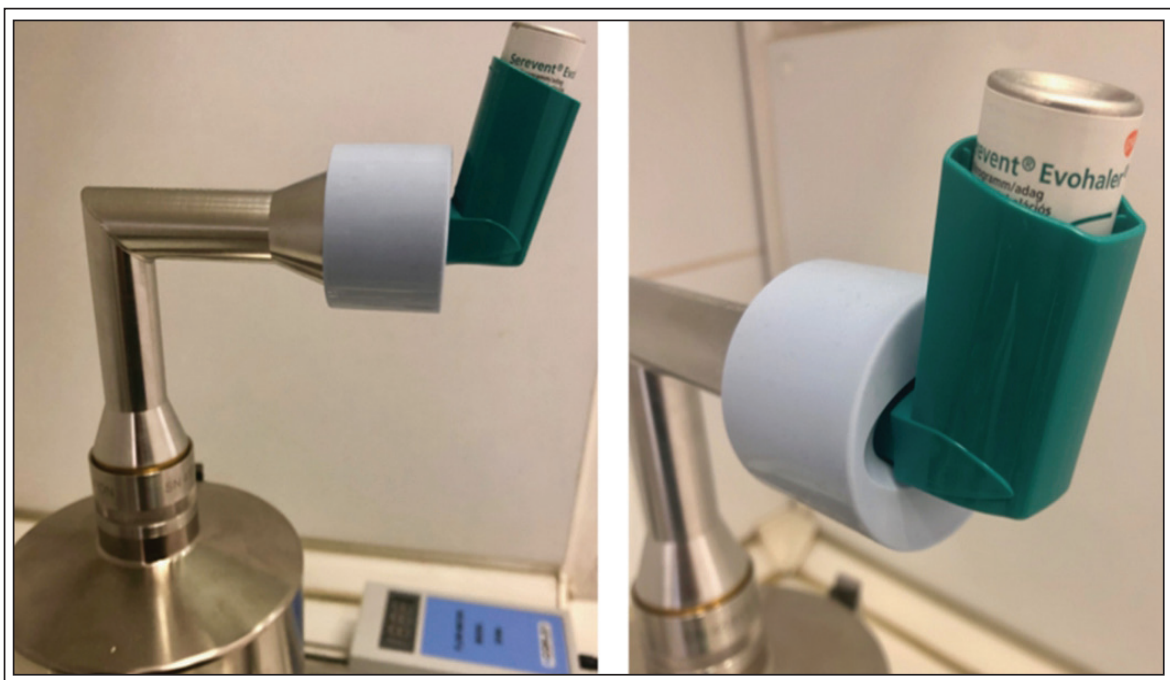

Figure 15 Evohaler placed on the induction port of the NGI

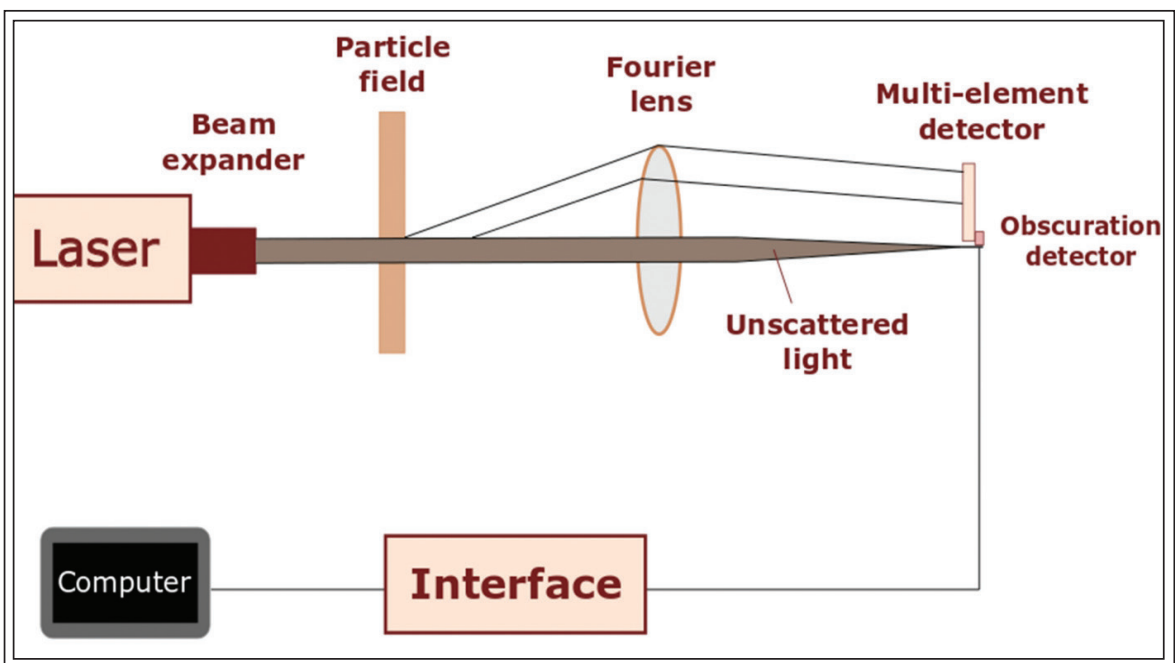

Figure 16 Laser diffraction particle size analyzer layout (based on [82]) bind these particles together. This can be achieved using the RODOS injection disperser (Sympatec Inc.). With RODOS, the compressed air injector provides an effective, long, and straight dispersion line of dry solid particles with a special flow control which can mix the particles with inert gas or compressed air. This high airflow, the jet formation and expansion provide an optimal aerosol cloud for the optical analysis without aggregation. Measurements directly from the aerosol cloud are also possible using systems such as HELOS (Sympatec Inc.), which provides a distribution analysis for powders and granules, but also wet samples such as suspensions, emulsions, and sprays $[80,84]$.

However, this technique possesses drawbacks as well: the measuring zone lacks a suitable air extraction which would be required in order to prevent the aerosol droplets from entering back into the laser beam. Air suction is also necessary to analyze how the inspiratory flow rate affects
- RODOS for dry dispersions

- HELOS (Helium-Neon Laser Optical System) laser diffraction sensor which can be connected to different inhalers (DPI, MDI, Soft mist inhalers)

- MYTOS which makes possible the in-line dry particle size analysis for automated laboratories All are developed by Sympatec Inc. They provide a precise particle size analysis for dry powders in the size range below $0.1 \mu \mathrm{m}$ to $4000 \mu \mathrm{m}$ for RODOS, $0.1 \mu \mathrm{m}$ to $8750 \mu \mathrm{m}$ for HELOS, and from $0.25 \mu \mathrm{m}$ to $3500 \mu \mathrm{m}$ for MYTOS [84].

In the case of dry powders, sampling before measuring is a significant step. An ineffective sampling technique will result in a wrong characterization of the powder. In laser diffraction, powder measurements can be carried out by dry dispersion, which aim is to enable the measurement of particles individually. This is done through the separation of particles agglomerates by suppressing the forces which the droplet size distribution. This shortage is explained by the fact that a junction is needed between the nebulizer's mouthpiece and the vacuum system in order to obtain a controlled air extraction. Nevertheless, it is not easily achievable and rather complicated to do so due to interferences with the laser beam. Other limitations include [80]:

- The calculation of volume distribution curves presuming that the particles possess a spherical shape.

- The inability to measure aerodynamic diameters (geometric particle diameters are measured instead).

- The inability to acquire fine particle mass fractions.

- The inability to measure low particle concentrations (dose weights $<4 \mu \mathrm{g}$ ).

- The inability to control the flow curve through the inhalation device. 
- Mixtures measurements (drug-drug or drug-excipients) are rather difficult.

- The measuring range is broader than the drug particles' size distribution: a $0.9 \mu \mathrm{m}-175 \mu \mathrm{m}$ range for a $100 \mathrm{~mm}$ lens, and a $0.45 \mu \mathrm{m}-87.5 \mu \mathrm{m}$ range for a $50 \mathrm{~mm}$ lens.

Nonetheless, laser diffraction remains a technique with several advantages, such as numerous size classes, precision, and a brief measuring time.

\subsection{Dissolution}

The study of adissolution behaviour is the study of a solid substance's potential to penetrate a solvent medium based on affinity characteristics. This provides useful information on the substance's absorption behaviour in vivo [17].

The dissolution profile of a dosage form constitutes an essential parameter for the bioavailability of any drug that is applied by a non-parenteral route. Factors that influence the dissolution behaviour of a drug include drug solubility, drug dose, formulation properties, drug particle properties, and the epithelial lining fluid (ELF) composition (which changes along the respiratory tract) [85]. In the lungs, the dissolution is the most significant in the small bronchioles and the alveoli, which constitute the segment where the majority of the drug absorption takes place. After inhalation, the fate of the drug particles is to dissolve in the ELF present along the respiratory tract. The ELF consists of a surfactant layer and an aqueous phase [85]. According to the region of the lungs where it is situated, the lining fluid differs in composition, thickness, and volume: the trachea, bron-

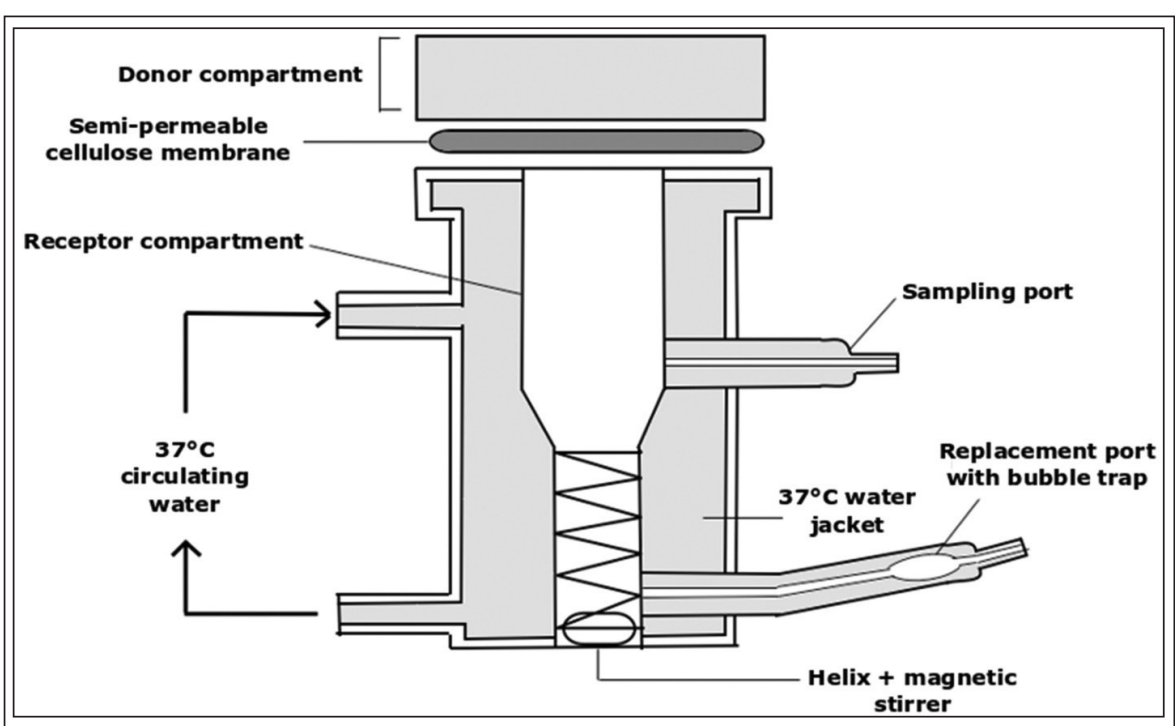

Figure 17 Franz Cell Model chi, and bronchioles are enveloped with a thick mucus gel (approximately $3-23 \mu \mathrm{m}$ ) whereas the alveolar region is covered with a particularly thin film (approximately $0.07 \mu \mathrm{m}$ ). The progressing thinning of the ELF results in physiological dissimilarities, which in turn induce difficulties in establishing the residence time of the particles by simulating lung conditions [86]. After inhalation, the particles which penetrate the non-ciliated segment of the pulmonary region will dissolve in the ELF. Only this dissolved portion of the dose administered will be accessible for absorption through the alveolar membrane [17].

Currently, the pharmacopoeia does not list any standard method for the dissolution testing of inhalation drugs despite the fact that several methods have been designed [17, 86, 87]. A certain number of methods are available to study conventional solid dosage forms, but they are intended for the simulation of the gastrointestinal tract and are therefore not suitable to study the dissolution of inhaled drugs (mainly due to their "sink" conditions") [17]. An example of these methods is the paddle over disc dissolution setup. This method enables the evaluation of the in vitro dissolution rate of inhaled formulations [88]. Another method is the flow-through cell apparatus, which studies the dissolution profile of poorly soluble glucocorticoids aerosols [89]. The dissolution profile of inhaled formulations can also be assessed using the diffusion-Franz cell apparatus. A study evaluating these three methods (the paddle over disc method, the flow through cell, and the diffusion-Franz cell apparatus) concluded that the Franz cell apparatus was the most promising [17, 90]. The Franz cell apparatus consists of a donor and receptor compartment. These two compartments are separated by a semi-permeable cellulose membrane. The powdered formulation is set on the bottom surface of a filter membrane, which is then positioned on the semi-permeable cellulose membrane. The drug will then dissolve and diffuse through the semi-permeable membrane. The study is done on samples gathered from the receptor compartment. The dissolved drug which diffuses through the 
membrane is analyzed by collecting the samples from the acceptor compartment (Figure 17).

Moreover, developing a method for the dissolution testing of an inhaled drug applicable to the lungs and their physiology can be quite complex due to the lungs' characteristics such as the small amount of their fluid. Besides, a separation of the API from the excipients should be done before testing [17]. However, a recent study developed an apparatus aiming to investigate the dissolution behaviour of anti-tubercular drugs powder formulations. This apparatus consists of a flow perfusion cell which symbolizes the air/blood perfusion. It employs a small volume of $25 \mu \mathrm{L}$ of unstirred, stationary medium to study the in vitro dissolution of inhalable drug particles, notably moxifloxacin and ethionamide, two anti-tubercular drugs. The particles of these two drugs were set on a sheet glass with the help of a Twin Stage Impinger. The mucus in which they should dissolve was simulated by polyethylene oxide (PEO) in a phosphate-buffered saline (PBS). Their dissolution profile was then investigated. The study concluded that ethionamide has a lower solubility and displayed a slower dissolution rate than moxifloxacin under all the dissolution conditions applied. The dissolution behaviour of ethionamide brought into question the dissolution mechanisms in small volumes of stationary medium (simulating the in vivo tracheobronchial region of the lungs). Such questions could be addressed using this method $[17,86,88]$.

The tracheobronchial region of the respiratory tract is covered with a viscoelastic blend containing glycoproteins, proteins, and lipids. However, the composition of this mucus may vary in case of diseases [91]. In testing conditions, an accurate simulation of in vivo parameters is continuously required. In dissolution testing, it can be achieved through the use of biological simulated lung fluids (SLF), which serve as dissolution media.

The SLF was first developed by Moss in 1979 [92]. This simulated fluid provides a greater comprehension of in vivo mechanisms. However, as seen previously, the development of a standardized dissolution method is a complex project due to the special characteristics of the lungs, such as the particularly small volume of fluid present.

Despite that, research was done to study a possible reproducible, standardized test method to investigate the dissolution profile of a micronized hydrocortisone pulmonary formulation. This method includes a dissolution test station (with mini-paddles, dissolution vessels, a water bath, and a sampling probe) and a membrane cassette. Among other things, the influence of the SLF composition on the dissolution rate was investigated. A modified version of the SLF (mSLF) was also used, which consists of $100 \mathrm{ml}$ of SLF $+200 \mu \mathrm{g} / \mathrm{mL}$ of $0.02 \%(\mathrm{w} / \mathrm{v})$ of dipalmitoylphosphatidylcholine (DPPC). The samples of hydrocortisone in SLF and mSLF were examined using an HPLC system. The mSLF yielded an increase in the release rate of hydrocortisone because a DPPC-containing medium may enhance the wettability of hydrophobic drugs and inhibit the aggregation of particles, therefore increasing the dissolution rate [88].

Another study designed a biorelevant SLF with distinct composition and characteristics (Table V), as well as directions for usage and storage [93].

\section{Conclusion}

Overall, it has been established that the pulmonary drug delivery demonstrates a significant relevance, notably due to the physiology of the lungs and their advantageous properties. Despite the presence of some disadvantages such as clearance mechanisms, pulmonary drug delivery continues to be a non-invasive route of administration that is preferred by patients. It has also been shown that pulmonary delivery is one of the oldest drug delivery methods. Since its first use, its application has gotten more and more elaborated. Nowadays, several types of inhalation devices are available on the market: nebulizers, MDIs, and DPIs. Supplementary devices such as spacers are also employable in order to achieve optimal results. The performance

Table V Composition and characteristics of a simulated lung fluid (based on [93])

\begin{tabular}{c|c}
\hline Composition & Physicochemical parameters \\
\hline Dipalmitoylphosphatidylcholine (DPPC) & $\mathrm{pH}=7.2$ \\
Dipalmitoylphosphatidylglycerol (DPPG) & Viscosity $=1.138 \times$ Pa.s \\
Cholesterol & Conductivity $=14.5 \mathrm{~ms}$ \\
Albumin & Surface tension $=54.9 \mathrm{mN} / \mathrm{m}$ \\
IgG & Density $=0.999 \mathrm{~g} / \mathrm{mL}$ \\
Transferrin & \\
Antioxidants & \\
\hline
\end{tabular}


and effectiveness of such inhalation devices depend partly on the particle size of the formulation used, as well as its deposition in the lungs. Such deposition is achieved by several mechanisms: diffusion, sedimentation, impaction, and interception. Furthermore, in order to assure the highest possible efficiency, formulations are developed following several criteria. Therefore, thorough testing is required to ensure the safety and quality of the end product. These tests are performed on both the formulation and the device which carries it. Investigations of the particle size and aerodynamic properties, for instance, can be done using laser diffraction and a cascade impactor.

Summing it up, the pulmonary drug delivery constitutes a considerably advantageous route of administration for local and systemic treatments of diseases. Nevertheless, the development of pulmonary dosage forms is a complex process which requires extensive considerations and meticulous optimizing.

\section{References}

1. de Boer, A.H., et al., Dry powder inhalation: past, present and future. Expert Opin Drug Deliv, 2017; 14: 499-512. https://doi.org/10.1080/17425247.2016.1 224846

2. Anderson, P.J. et al., History of Aerosol Therapy: Liquid Nebulization to MDIs to DPIs. Respir Care, 2005; 50: 1139.

3. Stein, S.W., C.G. Thiel, The History of Therapeutic Aerosols: A Chronological Review. J Aerosol Med Pulm Drug Deliv, 2017; 30: 20-41. https://doi. org/10.1089/jamp.2016.1297

4. Jackson, M. et al., "Divine stramonium": the rise and fall of smoking for asthma. Med Hist, 2010; 54: 171-194. https://doi.org/10.1017/S0025727300000235

5. Sanders, M. et al., Inhalation therapy: an historical review. Prim Care Respir J, 2007; 16: 71-81. https:// doi.org/10.3132/pcri.2007.00017

6. Hickey, A.J., Back to the future: inhaled drug products. J Pharm Sci, 2013; 102: 1165-72. https://doi. org/10.1002/jps.23465

7. Rajendran, R., et al., Recent modalities in drug delivery via inhalation therapy - An advanced treatment strategy for pulmonary Carcinoma. Int J Pharm Pharm Sci, 2015; 7: 8-21.

8. Han, B. and Hirahara, H., Effect of Gas OscillationInduced Irreversible Flow in Transitional Bronchioles of Human Lung. Journal of flow control measurement \& visualization, 2016; 4: 171-193. https:// doi.org/10.4236/jfcmv.2016.44015

9. Rangaraj, N., Pailla, S.R., Sampathi, S., Insight into pulmonary drug delivery: Mechanism of drug deposition to device characterization and regulatory requirements. Pulm Pharmacol Ther, 2019; 54: 1-21. https://doi.org/10.1016/j.pupt.2018.11.004
10. Yang, M.Y., Chan, J.G.Y., Chan, H.-K., Pulmonary drug delivery by powder aerosols. J Control Release, 2014; 193: 228-240. https://doi.org/10.1016/j. jconrel.2014.04.055

11. Dalby, R., Spallek, M., and Voshaar, T., A review of the development of Respimat ${ }^{\circledR}$ Soft Mist ${ }^{\mathrm{TM}}$ Inhaler. Int J Pharm, 2004; 283: 1-9. https://doi.org/10.1016/j. ijpharm.2004.06.018

12. Rudokas, M., et al., Liposome Delivery Systems for Inhalation: A Critical Review Highlighting Formulation Issues and Anticancer Applications. Med Princ Pract, 2016; 25 Suppl 2: 60-72. https://doi. org/10.1159/000445116

13. Lavorini, F., Fontana, G.A., and Usmani, O.S., New inhaler devices - the good, the bad and the ugly. Respiration, 2014; 88: 3-15. https://doi. org $/ 10.1159 / 000363390$

14. Thipphawong, J., et al., Pulmonary Insulin Administration Using the AERx ${ }^{\circledR}$ Insulin Diabetes System. Diabetes Technol The, 2002; 4: 499-504. https://doi. org/10.1089/152091502760306580

15. Radivojev, S., et al., Insights into DPI sensitivity to humidity: An integrated in-vitro-in-silico riskassessment. J Drug Deliv Sci Tec, 2019; 52: 803-817. https://doi.org/10.1016/j.jddst.2019.05.047

16. Norderud Laerum, B., Telg, G., Stratelis, G., Need of education for dry powder inhaler storage and retention - a patient-reported survey. Multidiscip Respir Med, 2016; 11: 21. https://doi.org/10.1186/s40248016-0057-0

17. Agu, R.U. and Ugwoke, M.I., In vitro and in vivo testing methods for respiratory drug delivery. Expert Opin Drug Deliv, 2011; 8: 57-69. https://doi.org /10.1517/17425247.2011.543896

18. $3 \mathrm{M}^{\mathrm{TM}}$ Drug Delivery Systems. Available from: https://www.3m.com/3M/en_US/drug-deliverysystems-us/technologies/inhalation/intelligentcontrol

19. Molimard, M., et al., Assessment of Handling of Inhaler Devices in Real Life: An Observational Study in 3811 Patients in Primary Care. J Aerosol Med, 2003; 16: 249-254. https://doi. org/10.1089/089426803769017613

20. Newman, S.P., Principles of Metered-Dose Inhaler Design. Respir Care, 2005; 50: 1177.

21. A Foss, S., W Keppel, J., In Vitro Testing of MDI Spacers: A Technique for Measuring Respirable Dose Output with Actuation In-Phase or Out-ofPhase with Inhalation. Respir Care, 1999; 44.

22. Kofman, C. Teper, A. Usefulness of Nonvalved Spacers for Administration of Inhaled Steroids in Young Children with Recurrent Wheezing and Risk Factors for Asthma. Can Respir J, 2018; 2018: 1-5. https://doi.org/10.1155/2018/3095647

23. Fonceca, A.M., et al., 16 - Drug Administration by Inhalation in Children in Kendig's Disorders of the Respiratory Tract in Children (Ninth Edition), 2019; 257-271.

24. Arora, P., et al., Evaluating the technique of using inhalation device in COPD and Bronchial Asthma patients. Resp Med, 2014; 108: 992-998. https://doi. org/10.1016/j.rmed.2014.04.021 
25. DePietro, M., et al., Inhalation device options for the management of chronic obstructive pulmonary disease. Postgrad Med, 2018; 130: 83-97. https://doi.org /10.1080/00325481.2018.1399042

26. Taffet, G.E., Donohue, J.F., Altman, P.R., Considerations for managing chronic obstructive pulmonary disease in the elderly. Clinical Interv Aging, 2013; 9: 23-30. https://doi.org/10.2147/CIA.S52999

27. O'Malley, C.A., Device Cleaning and Infection Control in Aerosol Therapy. Respir Care, 2015; 60: 91727. https://doi.org/10.4187/respcare.03513

28. Vincken, W., et al., Spacer devices for inhaled therapy: why use them, and how? ERJ Open Research, 2018; 4: 00065-2018. https://doi. org/10.1183/23120541.00065-2018

29. Guillon, A., et al., Insights on animal models to investigate inhalation therapy: Relevance for biotherapeutics. Int J Pharm, 2018; 536: 116-126. https://doi. org/10.1016/j.ijpharm.2017.11.049

30. Cha, M.L., Costa, L.R., Inhalation Therapy in Horses. Vet Clin North Am Equine Pract, 2017; 33: 29-46. https://doi.org/10.1016/j.cveq.2016.11.007

31. Chaturvedi, N.P., Solanki, H. Pulmonary drug delivery system: Review. Int J Appl Pharm, 2013; 5: 7-10.

32. Ozer, A.Y., Alternative Applications for Drug Delivery: Nasal and Pulmonary Routes, in Nanomaterials and Nanosystems for Biomedical Applications, M.R. Mozafari, Editor. 2007; Springer Netherlands: Dordrecht. 99-112. https://doi.org/10.1007/978-14020-6289-6_6

33. R Mathias, N., Hussain M., Non-invasive Systemic Drug Delivery: Developability Considerations for Alternate Routes of Administration. J Pharm Sci, 2010; 99: 1-20. https://doi.org/10.1002/jps.21793

34. Cohn, M.L., Davis, C.L., Middlebrook, G., Airborne Immunization against Tuberculosis. Science, 1958; 128: 1282. https://doi.org/10.1126/science.128.3334.1282

35. LiCalsi, C., et al., Dry powder inhalation as a potential delivery method for vaccines. Vaccine, 1999; 17: 1796-1803. https://doi.org/10.1016/S0264410X(98)00438-1

36. Shirley, M., Amikacin Liposome Inhalation Suspension: A Review in Mycobacterium avium Complex Lung Disease. Drugs, 2019; 79: 555-562. https://doi. org/10.1007/s40265-019-01095-Z

37. FDA. Available from: https://www.fda.gov/newsevents/press-announcements/fda-approves-newantibacterial-drug-treat-serious-lung-disease-using-novel-pathway-spur-innovation.

38. Rosenfeld, L., Insulin: Discovery and Controversy. Clin Chem, 2002; 48: 2270.

39. Elliott, R.B., et al., Parenteral absorption of insulin from the lung in diabetic children. Aust Paediatr J, 1987; 23: 293-7. https://doi. org/10.1111/j.1440-1754.1987.tb00275.x

40. Mastrandrea, L.D., Inhaled insulin: overview of a novel route of insulin administration. Vasc Health Risk Manag, 2010; 6: 47-58. https://doi.org/10.2147/ VHRM.S6098
41. Patton, J.S., Bukar J., Nagarajan S., Inhaled insulin. Adv Drug Deliv Rev, 1999; 35: 235-247. https://doi. org/10.1016/S0169-409X(98)00074-X

42. Owens, D.R., Zinman B., Bolli G., Alternative routes of insulin delivery. Diabetic Med, 2003; 20: 886-898. https://doi.org/10.1046/j.1464-5491.2003.01076.x

43. Heinemann, L., Inhaled Insulin: Dead Horse or Rising Phoenix? J Diabetes Sci Technol, 2017; 12: 239242. https://doi.org/10.1177/1932296817748231

44. Klonoff, D.C., Afrezza Inhaled Insulin: The Fastest-Acting FDA-Approved Insulin on the Market Has Favorable Properties. J Diabetes Sci Technol, 2014; 8: 1071-1073. https://doi. org/10.1177/1932296814555820

45. Pettus, J., Santos Cavaiola, T., Edelman, S.V., Recommendations for Initiating Use of Afrezza Inhaled Insulin in Individuals with Type 1 Diabetes. Diabetes Technol The, 2018; 20: 448-451. https://doi. org/10.1089/dia.2017.0463

46. Carvalho, T.C., Peters, J.I., Williams, R.O., 3rd, Influence of particle size on regional lung deposition-what evidence is there? Int J Pharm, 2011; 406: 1-10. https://doi.org/10.1016/j.ijpharm.2010.12.040

47. Telko, M.J., Hickey, A.J., Dry Powder Inhaler Formulation. Respir Care, 2005; 50: 1209.

48. Abhang, P., et al., Transmucosal Drug Delivery- An Overview. Curr Drug Deliv, 2014; 4. https://doi.org/ $10.2174 / 22103031113039990011$

49. Laube, B.L., et al., What the pulmonary specialist should know about the new inhalation therapies. Eur Respir J, 2011; 37: 1308-31. https://doi. org/10.1183/09031936.00166410

50. DeCarlo, P.F., et al., Particle Morphology and Density Characterization by Combined Mobility and Aerodynamic Diameter Measurements. Part 1: Theory. Aerosol Sci Tech, 2004; 38: 1185-1205. https:// doi.org/10.1080/02786826.2004.10399461

51. Abdellah, A., Noordin, M.I., Wan Ismail, W.A., Importance and globalization status of good manufacturing practice (GMP) requirements for pharmaceutical excipients. Saudi Pharm J, 2015; 23: 9-13. https://doi.org/10.1016/j.jsps.2013.06.003

52. Cripps, A., et al., Pharmaceutical transition to nonCFC pressurized metered dose inhalers. Respir Med, 2000; 94 Suppl B: S3-9. https://doi.org/10.1016/ S0954-6111(00)90147-1

53. Pilcer, G., Amighi K., Formulation strategy and use of excipients in pulmonary drug delivery. Int J Pharm, 2010; 392: 1-19. https://doi.org/10.1016/j. ijpharm.2010.03.017

54. El-Sherbiny, N.M., El-Baz, I.M., Yacoub, M.H., Inhaled nano- and microparticles for drug delivery. Glob Cardiol Sci \& Pract, 2015; 2015: 2-2. https://doi. org/10.5339/gcsp.2015.2

55. Ibrahim, M., Verma, R., Garcia-Contreras, L., Inhalation drug delivery devices: technology update. Med Devices (Auckl), 2015; 8: 131-139. https://doi. org/10.2147/MDER.S4888

56. Della Bella, A., et al., The role of the solid state and physical properties of the carrier in adhesive mixtures for lung delivery. Expert Opin Drug Deliv, 
2018; 15: 665-674. https://doi.org/10.1080/17425247. 2017.1371132

57. Kaialy, W., Nokhodchi, A., Dry powder inhalers: physicochemical and aerosolization properties of several size-fractions of a promising alterative carrier, freeze-dried mannitol. Eur J Pharm Sci, 2015; 68: 56-67. https://doi.org/10.1016/j.ejps.2014.12.005

58. Zhang, Q., et al., A Perspective on the Maillard Reaction and the Analysis of Protein Glycation by Mass Spectrometry: Probing the Pathogenesis of Chronic Disease. J Proteome Res, 2009; 8: 754-769. https:// doi.org/10.1021/pr800858h

59. Peng, T., et al., Influence of physical properties of carrier on the performance of dry powder inhalers. Acta Pharm Sin B, 2016; 6: 308-18. https://doi. org/10.1016/j.apsb.2016.03.011

60. Guchardi, R., et al., Influence of fine lactose and magnesium stearate on low dose dry powder inhaler formulations. Int J Pharm, 2008; 348: 10-7. https:// doi.org/10.1016/j.ijpharm.2007.06.041

61. Zeng, X.M., et al., The role of fine particle lactose on the dispersion and deaggregation of salbutamol sulphate in an air stream in vitro. Int J of Pharma, 1998; 176: 99-110. https://doi.org/10.1016/S03785173(98)00300-7

62. Jones, M.D., Price, R., The influence of fine excipient particles on the performance of carrier-based dry powder inhalation formulations. Pharm Res, 2006; 23: 1665-74. https://doi.org/10.1007/s11095006-9012-7

63. Young, P.M., et al., The influence of dose on the performance of dry powder inhalation systems. Int J Pharm, 2005; 296: 26-33.https://doi.org/10.1016/j. ijpharm.2005.02.004

64. Lavorini, F., Pistolesi, M., Usmani, O.S., Recent advances in capsule-based dry powder inhaler technology. Multidiscip Respir Med, 2017; 12: 11-11. https://doi.org/10.1186/s40248-017-0092-5

65. Edwards, D., Applications of capsule dosing techniques for use in dry powder inhalers. Ther Deliv, 2010; 1: 195-201. https://doi.org/10.4155/ tde. 10.1

66. Sibum, I., et al., Challenges for pulmonary delivery of high powder doses. Int J Pharm, 2018; 548: 325336. https://doi.org/10.1016/j.ijpharm.2018.07.008

67. Grasmeijer, F., et al., Recent advances in the fundamental understanding of adhesive mixtures for inhalation. Curr Pharm Des, 2015; 21: 5900-14. https:// doi.org/10.2174/1381612821666151008124622

68. Smith, I.J., Parry-Billings M., The inhalers of the future? A review of dry powder devices on the market today. Pulm Pharmacol Ther, 2003; 16: 79-95. https:// doi.org/10.1016/S1094-5539(02)00147-5

69. Uddin, M.S., et al., Pharmacopoeial Standards and Specifications for Pharmaceutical Aerosols: In-Process and Finished Products Quality Control Tests, 2016; 6: 1-12. https://doi.org/10.9734/ AIR/2016/22442

70. Mahler, D.A., Peak Inspiratory Flow Rate as a Criterion for Dry Powder Inhaler Use in Chronic Obstructive Pulmonary Disease. Ann Am Thorac
Soc, 2017. 14: 1103-1107. https://doi.org/10.1513/ AnnalsATS.201702-156PS

71. Dal Negro, R.W., Dry powder inhalers and the right things to remember: a concept review. Multidiscip Respir Med, 2015; 10: 13 https://doi.org/10.1186/ s40248-015-0012-5

72. Lumb, A.B., Nunn's applied respiratory physiology, 8th edition. 2017; /10.1016/B978-0-7020-62940.00025-3

73. Weuthen, T., et al., In vitro testing of two formoterol dry powder inhalers at different flow rates. J Aerosol Med, 2002; 15: 297-303. https://doi. org/10.1089/089426802760292636

74. Copley. Quality Solutions for Inhaler Testing. 2019; Brochure available from: https://www.copleyscientific.com/files/ww/brochures/Inhaler\%20Testing\%20Brochure\%202019_Low\%20\%20Res.pdf.

75. Marple, V.A., et al., Next generation pharmaceutical impactor (a new impactor for pharmaceutical inhaler testing). Part I: Design. J Aerosol Med, 2003; 16: 283-99. https://doi.org/10.1089/089426803769017659

76. 2.9.18. Preparations for inhalation: aerodynamic assessment of fine particles, in European Pharmacopoeia 8.0. 2014; 309-321.

77. Dekhuijzen, P.N.R., Lavorini, F., Usmani, O.S., Patients' perspectives and preferences in the choice of inhalers: the case for Respimat ${ }^{(\mathbb{})}$ or HandiHal$\mathrm{er}^{(\circledast)}$. Patient Prefer Adherence, 2016; 10: 1561-1572. https://doi.org/10.2147/PPA.S82857

78. Atkins, P.J., Dry Powder Inhalers: An Overview. Respir Care, 2005; 50: 1304.

79. Chaplin, S., Walker, P., Long-acting bronchodilators: their properties and place in treatment. Prescriber, 2011; 22: 28-32. https://doi.org/10.1002/psb.801

80. de Boer, A.H., et al., Characterization of inhalation aerosols: a critical evaluation of cascade impactor analysis and laser diffraction technique. Int J Pharm, 2002; 249: 219-231. https://doi.org/10.1016/S03785173(02)00526-4

81. Ho, K.K.L., Kellaway, I.W., Tredree, R., Particle Size Analysis of Nebulised Aerosols Using Fraunhofer Laser Diffraction and Inertial Compaction Methods. J Pharm Pharmacol, 1986; 38. https://doi. org/10.1111/j.2042-7158.1986.tb14255.x

82. Ma, Z., et al., New developments in particle characterization by laser diffraction: size and shape. Powder Technol, 2000; 111: 66-78. https://doi.org/10.1016/ S0032-5910(00)00242-4

83. Ziegler, J., Wachtel, H., Comparison of Cascade Impaction and Laser Diffraction for Particle Size Distribution Measurements. J Aerosol Med, 2005; 18: 311324. https://doi.org/10.1089/jam.2005.18.311

84. Sympatec Inc.; Available from: https://www.sympatec.com/en/.

85. Radivojev, S., et al., Searching for physiologically relevant in vitro dissolution techniques for orally inhaled drugs. Int J Pharm, 2019; 556: 45-56. https:// doi.org/10.1016/j.ijpharm.2018.11.072

86. Eedara, B.B., Tucker, I.G., Das, S.C., In vitro dissolution testing of respirable size anti-tubercular drug particles using a small volume dissolution appa- 
ratus. Int J Pharm, 2019; 559: 235-244. https://doi. org/10.1016/j.ijpharm.2019.01.035

87. May, S., et al., Dissolution techniques for in vitro testing of dry powders for inhalation. Pharm Res, 2012; 29: 2157-66. https://doi.org/10.1007/s11095-012-0744-2

88. Son, Y.J., McConville, J.T., Development of a standardized dissolution test method for inhaled pharmaceutical formulations. Int J Pharm, 2009; 382: 1522. https://doi.org/10.1016/j.ijpharm.2009.07.034

89. Davies, N.M., Feddah, M.R., A novel method for assessing dissolution of aerosol inhaler products. Int J Pharm, 2003; 255: 175-87.https://doi.org/10.1016/ S0378-5173(03)00091-7

90. Salama, R.O., et al., Preparation and characterisation of controlled release co-spray dried drug- polymer microparticles for inhalation 2: evaluation of in vitro release profiling methodologies for controlled release respiratory aerosols. Eur J Pharm Biopharm, 2008; 70: 145-52. https://doi.org/10.1016/j. ejpb.2008.04.009

91. Marques, M., Löbenberg, R., Almukainzi, M., Simulated Biological Fluids with Possible Application in Dissolution Testing. Dissolut Technol, 2011; 18: p.15-28. https://doi.org/10.14227/DT180311P15

92. R Moss, O., Simulants of lung interstitial fluid. Health Phys, 1979; 36: 447-8.

93. Hassoun, M., et al., Design and development of a biorelevant simulated human lung fluid. J Drug Deliv Sci Technol, 2018; 47: 485-491. https://doi. org/10.1016/j.jddst.2018.08.006 